\title{
Insight on Fruit Fly IPM Technology Uptake and Barriers to Scaling in Africa
}

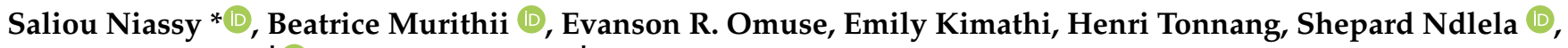 \\ Samira Mohamed ${ }^{+}\left(\mathbb{D}\right.$ and Sunday Ekesi ${ }^{\dagger}$
}

Citation: Niassy, S.; Murithii, B.; Omuse, E.R.; Kimathi, E.; Tonnang, H.; Ndlela, S.; Mohamed, S.; Ekesi, S. Insight on Fruit Fly IPM Technology Uptake and Barriers to Scaling in Africa. Sustainability 2022, 14, 2954. https://doi.org/10.3390/su14052954

Academic Editor: Diego Luis Valera Martínez

Received: 19 December 2021 Accepted: 24 February 2022 Published: 3 March 2022

Publisher's Note: MDPI stays neutral with regard to jurisdictional claims in published maps and institutional affiliations.

Copyright: (C) 2022 by the authors. Licensee MDPI, Basel, Switzerland. This article is an open access article distributed under the terms and conditions of the Creative Commons Attribution (CC BY) license (https:/ / creativecommons.org/licenses/by/ $4.0 /)$.
International Centre of Insect Physiology and Ecology (ICIPE), Nairobi 30772-00100, Kenya; bmuriithi@icipe.org (B.M.); eomuse@icipe.org (E.R.O.); ekimathi@icipe.org (E.K.); htonnang@icipe.org (H.T.); sndlela@icipe.org (S.N.); sfaris@icipe.org (S.M.); sekesi@icipe.org (S.E.)

* Correspondence: sniassy@icipe.org

+ These authors contributed equally to this work.

\begin{abstract}
Tephritid fruit flies are considered one of the world's most notorious pests of horticultural crops, causing extensive direct and indirect damage. Over the past two decades, a comprehensive, integrated pest management (IPM) package for the management of a plethora of fruit fly pests, including Bactrocera dorsalis, B. latifrons, B. zonata, Ceratitis cosyra, C. rosa, C. fasciventris, C. quilici, C. capitata, Dacus spp. and Zeugodacus cucurbitae, has been developed, disseminated and promoted among horticultural growers in Africa. To estimate the numbers of beneficiaries reached by the fruit fly IPM technology and the barriers to technology uptake, we interviewed 290 experts in 30 African countries covering five regions of the continent, and the responses collected were represented as follows: Southern Africa (39.1\%), Eastern Africa (31.6\%), Western Africa (18.0\%), Central Africa (9.0\%) and Northern Africa $(2.0 \%)$. Our results revealed that the use of fruit fly IPM technologies varied across the regions, with Eastern Africa and Western Africa the leading regions, with the highest IPM technology penetration. Field sanitation remains the most common practice for managing fruit flies, followed by protein bait spray, use of biopesticides, male annihilation technique and parasitoid releases. According to the survey, over 101 million people have benefited from the fruit fly IPM interventions in the countries surveyed representing only $19.1 \%$ of the estimated beneficiaries. The region that benefitted the most was Eastern Africa (50.2 million), followed by Central and Western Africa (11.7 to 17.7 million), and Southern and Northern Africa had the fewest beneficiaries (10.4 to 11.0 million). The limitations to the IPM technologies uptake varied among the regions, but the common ones include a lack of awareness of the IPM technologies, a lack of access to the IPM products, insufficient training, a low involvement of private sectors and a lack of policies for the regulation of IPM technologies. Although significant strides have been made in promoting the fruit fly IPM technologies over the past two decades, our study reveals that the demand surpasses the current supply. Our study recommends a comprehensive strategy for the dissemination and promotion of the technologies through a multi-institutional alliance that enhances public and private partnerships, digital platforms and youth engagement to consolidate previous gains at the regional and continental levels.
\end{abstract}

Keywords: horticulture; fruit flies; IPM technologies; beneficiaries; Africa

\section{Introduction}

Horticulture is one of the most important agricultural sectors for many African countries, revitalising rural economies and alleviating poverty through increased farm profits, employment generation and economic diversification [1]. A diversification into horticulture should contribute to poverty eradication by providing income and employment to poor rural households, especially women and youths, the expansion into the agro-processing and processed food marketing and a minimization of food and nutritional insecurity, while helping to restore the equilibrium in the balance of payments by increasing the total export 
earnings for African countries as well as reducing fluctuations in the revenues from exports [2,3]. Although growth in the horticulture sub-sector presents many opportunities for improving food and nutritional security and growing the rural economies and livelihoods of the poor populace, it faces threats from insect pests. For instance, tephritid fruit flies are known to cause extensive economic losses to horticultural crops throughout Africa [3-11].

Sub-Saharan Africa (SSA) alone is the aboriginal home to 915 fruit fly species from 148 genera, out of which 400 species develop in either wild or cultivated fruit or both. They belong mainly to three genera: Ceratitis, Dacus and Trirhithrum, which cause between 25\% (Ceratitis and Trirhithrum) and 62\% (Dacus) damage to fruits and vegetables [4,12-15]. With the intensification of international fruit trade, the continent is also highly vulnerable to the introduction and spread of alien invasive fruit fly species, including Bactrocera zonata (Saunders), B. latifrons (Hendel), Zeugodacus cucurbitae (Coquillett) and B. dorsalis (Hendel) $[4,15-18]$. The damage by $B$. dorsalis to mango, for instance, is estimated to vary from 40 to $90 \%$ depending on the location, the cultivar and the seasons in Eastern, Central, Western and Southern Africa $[5,8,11,19,20]$, while in Northern Africa, Medfly Ceratitis capitata (Wied.) is wreaking havoc [21-23]. In addition, indirect losses attributed to the quarantine restrictions imposed by importing countries to prevent the entry and establishment of fruit flies are estimated at $\$ 2$ billion annually in Africa [14]. The direct and indirect damage continue to have wide-reaching socio-economic implications, including the loss of jobs, income and trade for millions of rural and urban populations involved in the horticulture value chains across Africa.

The African Fruit Fly Program (AFFP) was established in response to requests from African fruit growers, national governments and regional commodity and quarantine bodies to address the fruit fly problem in Eastern, Central, Western and Southern Africa. Similar fruit fly IPM initiatives have been implemented in Northern Africa, particularly in Tunisia, Morocco and Egypt [7,22-24].

Prior to these interventions, the use of broad-spectrum insecticides was the only management strategy available to smallholder growers in the programme's target regions. Synthetic insecticides are highly unreliable due to the multivoltine and concealed habit of fruit flies in the Bactrocera and Ceratitis genera and resistance build-up [24]. The injudicious application of these insecticides seriously compromises human and environmental health and negatively affects beneficial ecosystem service providers such as natural enemies and pollinators [25]. In addition, insecticides are costly to resource-constrained smallholders, and high residual levels in fruit reduce competitiveness, especially on international markets [26]. To overcome these challenges, fruit fly control programmes such as the AFFP have implemented one of the most comprehensive IPM measures in Africa in line with the demand for socio-economic impact and ecosystem sustainability [27]. The various fruit fly IPM tactics target different developmental stages (i.e., egg, larva, pupae, adult male or female) of the different fruit fly species (Ceratitis cosyra (Walker), C. rosa Karsch, C. fasciventris Bezzi, C. quilicii De Meyer, Mwatawala \& Virgilio, C. anonae Graham, C. capitata Wiedemann, B. dorsalis, B. zonata, B. latifrons and Z. cucurbitae) $[7,19,28]$. The postharvest treatment targeting B. dorsalis, C. capitata and C. rosa based on hot water treatments for mangoes and cold treatments for citrus and avocado fruits have also been developed and disseminated jointly with the private sectors [29].

The IPM strategy comprises a menu of multiple tactical and ecological processes of prevention, monitoring and control that are based on understanding fruit fly's behaviour, biology and ecology. When carefully combined, IPM strategies suppress the fruit fly population in an environmentally and cost-effective manner that generates higher yields and fruits that are pest and chemical-free. For example, the use of two management components (bait spray and fungus-based biopesticides) against $B$. dorsalis was estimated to increase the net income of smallholder mango growers by $48 \%$ relative to the control group, while insecticide use and mango rejection were reduced by $46.4 \%$ and $54.5 \%$, respectively $[28,30]$. A more recent study reported that the adoption of two or three components of the IPM package provided yield gains of $27 \%$ and $95 \%$ and corresponding income impacts of $33 \%$ 
and 137\%, respectively [31]. Consequently, the use of IPM measures reduced the environmental impact quotient and the environmental risk effects associated with insecticide use and preserved human health $[27,31]$. Overall, the combined IPM package with biopesticide, male annihilation and baiting techniques reduced mango infestation by fruit flies by $>80 \%$, increased mango revenues by up to $60 \%$ and reduced insecticide use and their adverse health and environmental effects (e.g., skin rashes, coughing, reduction in pollinator biodiversity) by $74 \%$ and $23-35 \%$, respectively [27,31]. Muriithi et al. [32] reported that African farmers can adopt fruit fly IPM technologies that are affordable and easier to apply and showed that about $47 \%$ of mango growing households were willing to pay for fruit fly IPM technology in Ethiopia. Similar findings have also been reported in Kenya [33]. When effectively coupled with technology transfer and partnerships between the public and private sectors, the fruit fly IPM tactics could be successfully scaled out. Despite the success reached through the introduction and scaling of the fruit fly IPM innovations, there has been no attempt to systematically document the number of beneficiaries and the impact at the national, regional and continental scale.

Generally, project implementers and development partners often aim to effectively utilise project resources to reach the highest possible number of beneficiaries. Nevertheless, development literature did not focus much on tracking the number of project beneficiaries resulting from a successful implementation, perhaps due to the challenges associated with measuring it [34]. According to Okello [34], difficulties typically arise with tracing and recording information about households or individuals that benefit directly or indirectly from IPM programmes; instead, much attention is diverted to approaches for measuring the effect of the interventions.

In this study, we attempted to measure the number of beneficiaries that the fruit fly IPM interventions have reached in Eastern, Central, Northern, Western and Southern Africa. Utilising a targeted stakeholder mapping through an online survey of IPM practitioners in Africa, this study documents the penetration of the fruit fly technological innovation and use in the continent and estimates the number of beneficiaries in the various regions. The study also identified the barriers to a large-scale uptake of IPM technologies to guide further scaling strategies and dissemination pathways.

\section{Materials and Methods}

\subsection{The Questionnaire and Survey}

The data utilised in this study were obtained using a questionnaire embedded in Microsoft forms that were widely circulated to various stakeholders in the horticultural industry using Mailchimp. The first part of the questionnaire consisted of respondent information, affiliation and contact details; the second part examined the fruit fly IPM strategies and the frequently used technologies; the third part focused on estimating the number of beneficiaries; finally, the survey investigated the challenges to technological uptake to guide the development of a strategy to enhance the dissemination and use of the fruit fly management toolbox. For the purpose of this survey, we define a beneficiary as an individual who has been directly or indirectly reached by the fruit fly initiatives [34].

The questionnaire was available in both English and French, and an MS-Word format of the same questionnaire was also shared with individuals who could not access the online survey. The questionnaire targeted entomologists, policymakers, private sector practitioners and students with an interest in fruit fly research for development across 54 African countries. The online questionnaire also enabled the respondents to share additional documents (publications, reports, thesis), which were further verified using Google or Web of Science during intensive data mining to identify any anomalies, patterns and correlations within the larger dataset as submitted by the respondents. The questionnaire was circulated from 1 November 2020 until 8 December 2021, when no further responses came through the public interface. 


\subsection{Data Analysis}

The data were downloaded from the Microsoft forms platform, cleaned, rearranged and sorted to enhance clarity before the analysis. Additional direct emails and phone calls were made to fill in missing data. Redundant data were clarified or removed. Simple stepwise descriptive analyses were performed by aggregating data nationally and regionally according to fruit fly IPM technologies and their combinations.

Geographic Information System (GIS) applications were used to project results on maps. To reduce biases and to harmonise the response per country and region, data were converted into proportions (\%). The numbers of beneficiaries indicated by the respondents were aggregated per country and region. Responses referring to the same IPM programme, year and location were averaged. IPM technology integration levels were analysed using logistic regression. In this model, regions and countries were the predictor variables. All respondents who confirmed the usage of IPM technologies in their respective countries listed at least one of the six IPM technologies (field sanitation, protein bait spray, biopesticide, male annihilation technique, parasitoid releases and sterile insect technique) provided in our survey. Data on the technology usage were further sorted into three scores (3: practised, 2: fairly practised, and 1: least practised) using a clustering analysis for the regions. The respondents indicated the estimated number of beneficiaries of IPM technologies, which were clustered into the following intervals, based on the ranges provided in the questionnaire (0-100; 100-1000; 1000-10,000; 10,000-100,000; 100,000-1,000,000; >1,000,000), and the respondents indicated the range of beneficiaries for the IPM technologies that are widely used in the region. The number of beneficiaries within the countries and regions was analysed using the generalised linear model (GLM) with the negative binomial distribution.

To estimate the potential number of beneficiaries beyond the data generated from the survey, gridded spatial data on the total population and the population of tropical fruit growers within the surveyed countries (2020 projected population density) were sourced from the National Aeronautics and Space Administration (NASA) Socioeconomic Data and Applications Center (SEDAC) (https:/ / sedac.ciesin.columbia.edu/data/collection/ gpw-v4/sets/browse, accessed on 15 December 2021) and the International Food Policy Research Institute (IFPRI) HarvestChoice Dataverse (https: / /www.mapspam.info / data /, accessed on 15 December 2021), respectively. The population laying in the tropical growing regions was calculated for each surveyed country using the cell statistical tool implemented in the Raster package [35]. We also sourced data from FAO's latest projection (2019) for the production capacity of tropical fruits (mainly attacked by fruit flies, e.g., mango, citrus, avocado, papaya, custard apple, banana, peach, guava, etc.) [36]. The estimated tropical fruit-growing populations were considered as potential IPM beneficiaries of technologies. We correlated these data with the estimated number of beneficiaries from our survey, as explained above, using Principal Component Analysis (PCA) for the African continent and summarised the correlations for the countries using balloon plots. The most frequent challenges to the technological scale-up were expressed as a proportion and sorted into three clusters based on their importance. All statistics were performed using R Software, version 4.0.5, Vienna, Austria [37], and the significance level was kept at $p=0.05$.

\section{Results}

\subsection{Responses and Fruit Fly IPM Initiatives}

A total of 290 responses from 30 African countries covering all five regions of the continent were received with the following distribution: Southern Africa (39.1\%), Eastern Africa (31.6\%), Western Africa (18.0\%), Central Africa (9.0\%) and Northern Africa (2.0\%). Among the respondents, $75 \%$ were researchers and policymakers, $15 \%$ students and $10 \%$ from the private sector. Of all the respondents, $96 \%$ have been involved in fruit fly IPM research for development in their respective countries. Only $4 \%$ of respondents were unaware of fruit fly IPM activities in their countries.

Our results show that fruit fly IPM activities have been implemented across Eastern, Western, Central, Northern and Southern Africa (Figure 1A). The survey reports at 
least 100 fruit fly IPM initiatives implemented across the 30 countries from which we received responses. These initiatives were mainly donor-funded programmes implemented by international research organisations, national agricultural research and extension systems, non-governmental organizations (NGOs), the private sector and diverse universities through international cooperation (Figure 1B).

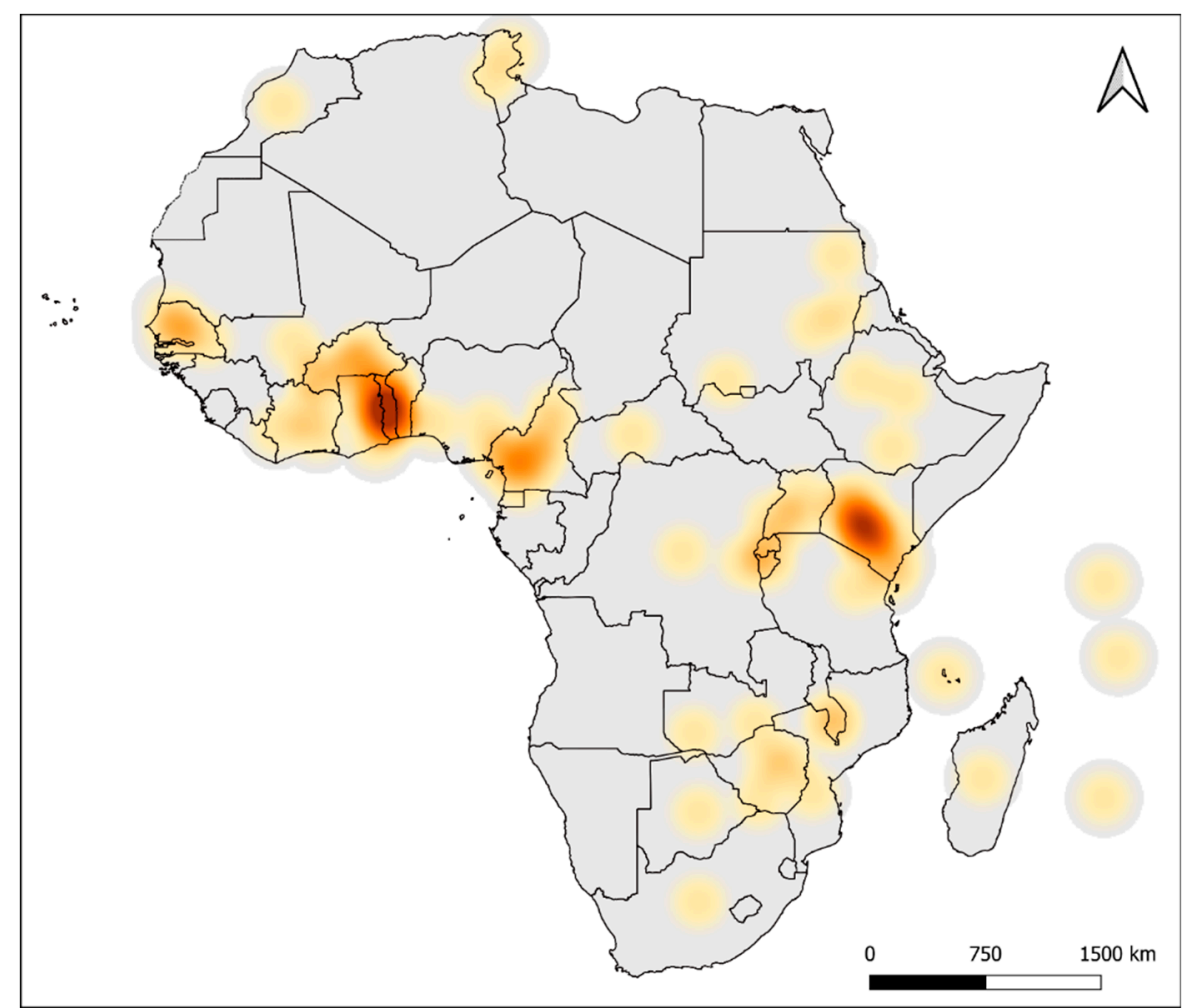

(A)

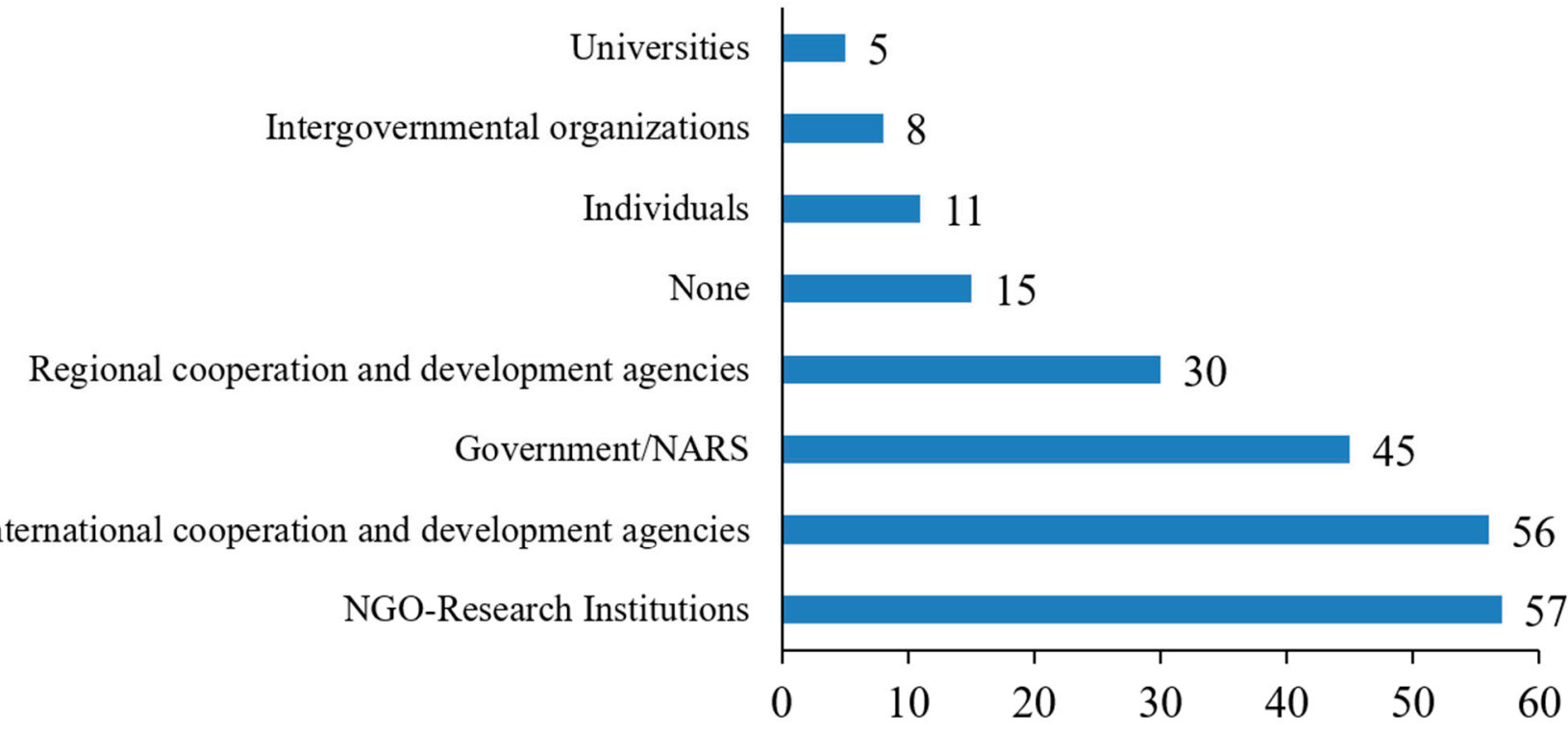

Number of projects implemented by different actors

(B)

Figure 1. Location (A) and partnership distribution (B) of fruit fly IPM initiatives in Africa. Note: NARS = National Agricultural Research Systems. NGO = Non-Governmental Organization . 


\subsection{Fruit Fly IPM Technological Usage in Africa}

Field sanitation was the most used fruit fly management practice as cited by respondents, followed by protein bait spray, biopesticides, male annihilation technique (MAT) and parasitoid releases. In contrast, the sterile insect technique (SIT) was the least accessible technology in Africa (Figure 2).

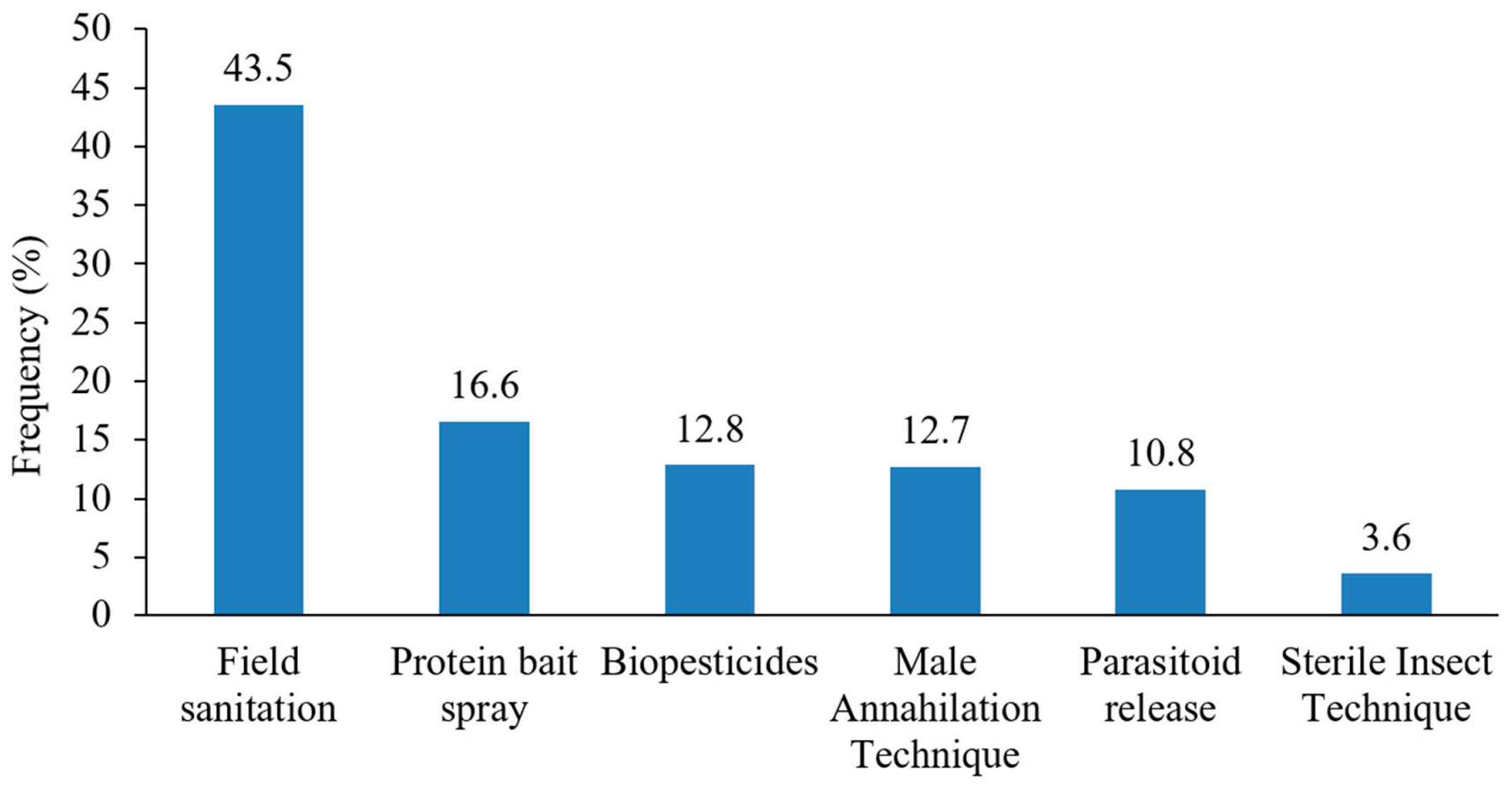

Fruit fly IPM practices

Figure 2. The frequency of fruit fly IPM practices in Africa.

The clustering of responses showed a disparity between regions, suggesting that fruit fly IPM technologies have been disproportionately taken up and applied across the regions (Figure 3). Overall, Eastern and Western Africa were the leading regions in fruit fly IPM technological usage (Figure 3). The technologies are least used in Central and Northern Africa. Field sanitation has mostly been practised in Northern and Southern Africa, followed by Western and Eastern Africa, and least practised in Central Africa (Figure 3). The use of MAT was highest in Eastern and Southern Africa, followed by Western Africa, and lowest in Northern and Central Africa (Figure 3). Biopesticides have been widely used in Northern and Western Africa compared to other regions. Eastern, Northern, Western and Southern Africa had a significant utilization of protein bait spray. Parasitoid releases were highest in Eastern and Western Africa, followed by Central Africa, and lowest in Northern Africa (Figure 3).

Based on the high level of responses $(16.0 \%)$, the number of fruit fly projects and the diverse technologies being used in Kenya, we use the country as a reference in our regression models. Our results showed that Cameroon had the lowest score in terms of the use of field sanitation and MAT for fruit fly control (Table 1). In addition, biopesticides are significantly used in Sudan and Mozambique compared to other countries (Table 1). Senegal is quite advanced in parasitoid releases for fruit fly control, while Sudan lagged behind (Table 1). 
Field sanitation

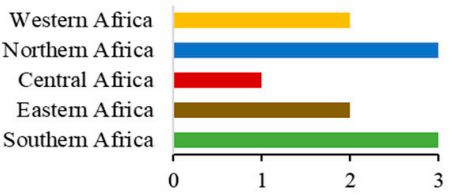

Male Annihilation Technique

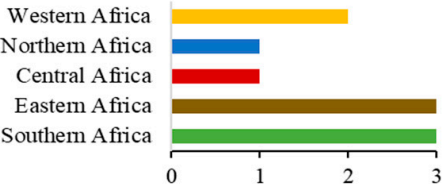

Protein bait

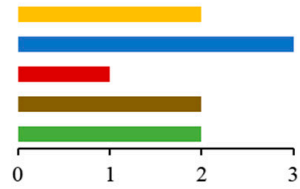

Parasitoid release

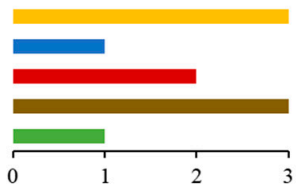

Biopesticides

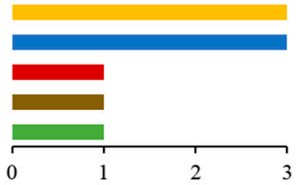

Sterile Insect Technique

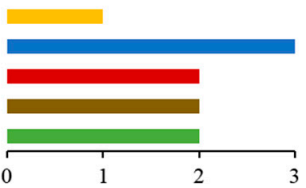

Figure 3. Cluster analysis of individual IPM technology practices in five African regions. Note: The technological use across the regions were sorted into 3 clusters; practised (3), fairly practised (2) and least practised (1). Cluster analysis of five African regions on the extent of application of an individual IPM technology. Note: The regions were sorted into 3 clusters according to whether they practise (3), fairly practise (2) and least practise (2) an individual IPM technology.

Figure 4 depicts the frequency of mention of the fruit fly technologies across various countries in Africa. The results obtained from this survey revealed that Kenya, Burkina Faso, Senegal, Zimbabwe, Cameroon and Sudan are the leading countries using fruit fly IPM technologies on the target regions (Figure 4).

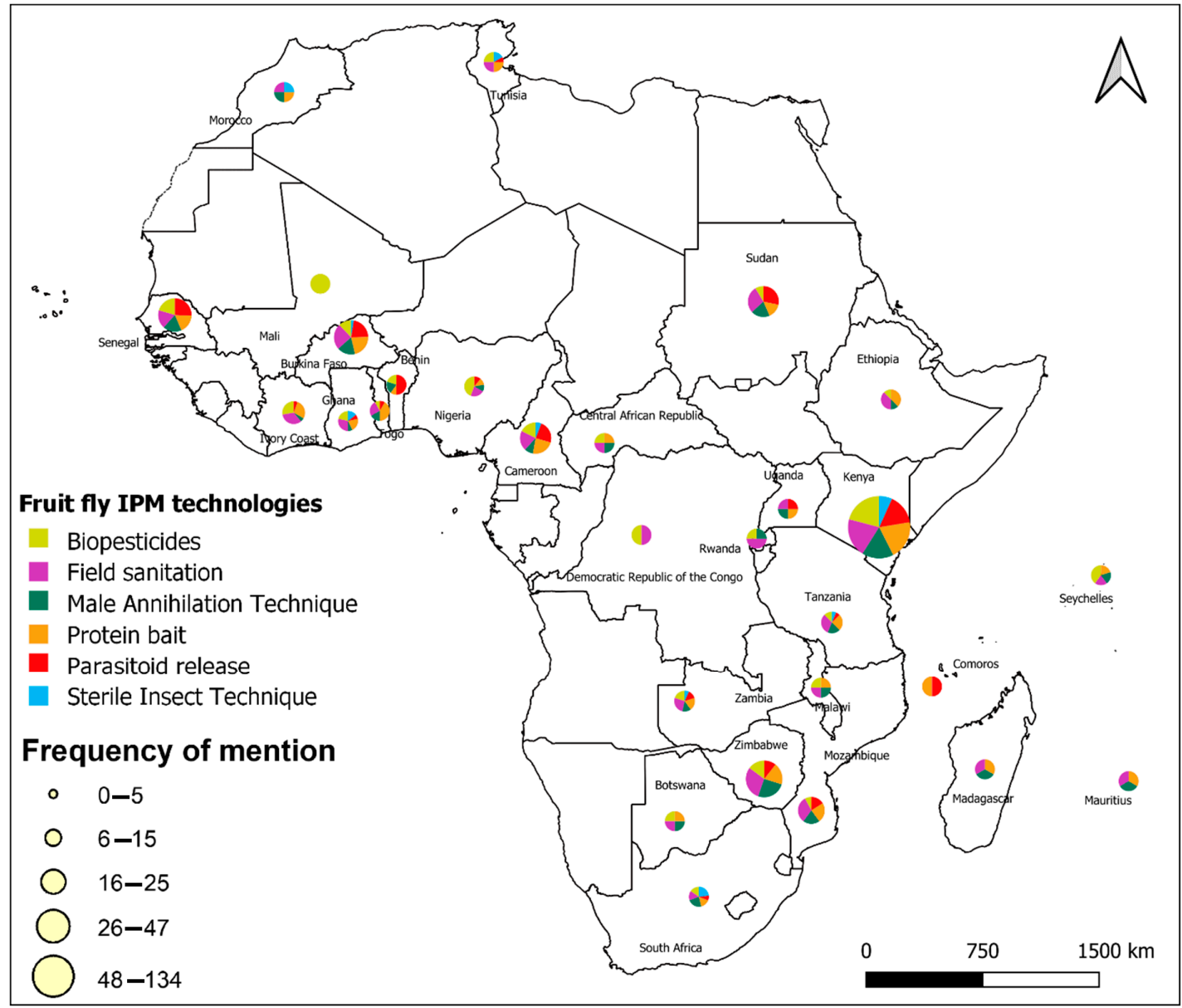

Figure 4. The commonly used fruit fly IPM technologies in Africa. 
Table 1. Estimates of regression parameter based on logistic regression for the use of fruit fly IPM technologies across fruit-growing countries in Africa using Kenya as reference country.

\begin{tabular}{|c|c|c|c|c|c|c|c|c|c|c|c|c|c|c|c|c|c|c|}
\hline \multirow[t]{3}{*}{ Countries } & \multicolumn{18}{|c|}{ IPM Technologies } \\
\hline & \multicolumn{3}{|c|}{ Field Sanitation } & \multicolumn{3}{|c|}{ a MAT } & \multicolumn{3}{|c|}{ Biopesticides } & \multicolumn{3}{|c|}{ Protein Bait Spray } & \multicolumn{3}{|c|}{ Parasitoid Releases } & \multicolumn{3}{|c|}{ b SIT } \\
\hline & Estimate & Z Score & & Estimate & Z Score & & Estimate & Z Score & & Estimate & Z Score & & Estimate & Z Score & & Estimate & Z Score & \\
\hline $\begin{array}{l}\text { Burkina } \\
\text { Faso }\end{array}$ & 0.847 & 0.999 & ns & 0.413 & 0.589 & ns & -1.216 & -1.718 & ns & 0.431 & 0.574 & ns & 0.932 & 1.250 & ns & -1.171 & -1.055 & ns \\
\hline Cameroon & -1.262 & -2.087 & $*$ & -1.325 & -2.033 & * & -1.013 & -1.710 & ns & -0.432 & -0.740 & ns & -0.166 & -0.288 & ns & -0.883 & -1.057 & $\mathrm{~ns}$ \\
\hline Ethiopia & -0.251 & -0.259 & ns & -1.532 & -1.320 & ns & -2.043 & -1.753 & ns & -0.144 & -0.149 & ns & -17.614 & -0.010 & ns & -18.434 & -0.004 & $\mathrm{~ns}$ \\
\hline Ghana & 17.909 & 0.005 & ns & -0.839 & -0.664 & ns & 0.036 & 0.029 & ns & 16.020 & 0.012 & ns & -0.741 & -0.587 & ns & 0.438 & 0.343 & $\mathrm{~ns}$ \\
\hline Mozambique & 17.909 & 0.008 & ns & 0.364 & 0.458 & $\mathrm{~ns}$ & -1.755 & -1.994 & * & 0.548 & 0.624 & ns & -0.048 & -0.063 & ns & -18.434 & -0.005 & ns \\
\hline Nigeria & 0.036 & 0.029 & ns & -16.712 & -0.012 & ns & 16.909 & 0.007 & ns & -1.243 & -0.981 & ns & -0.741 & -0.587 & ns & -18.434 & -0.003 & ns \\
\hline Senegal & -0.097 & -0.137 & ns & 0.413 & 0.589 & ns & 0.324 & 0.430 & ns & 0.010 & 0.014 & ns & 2.253 & 2.059 & * & -18.434 & -0.006 & $\mathrm{~ns}$ \\
\hline Sudan & 1.828 & 1.675 & ns & 0.6643 & 0.980 & $\mathrm{~ns}$ & -1.467 & -2.142 & * & -0.395 & -0.615 & ns & -2.533 & -2.332 & * & -1.353 & -1.228 & ns \\
\hline Tanzania & 0.952 & 0.833 & $\mathrm{~ns}$ & 0.143 & 0.555 & $\mathrm{~ns}$ & -1.573 & -1.750 & $\mathrm{~ns}$ & -0.147 & -0.168 & $\mathrm{~ns}$ & -1.658 & -1.456 & $\mathrm{~ns}$ & -0.478 & -0.414 & $\mathrm{~ns}$ \\
\hline Togo & 0.441 & 0.368 & ns & -1.2452 & -1.041 & ns & -1.755 & -1.462 & ns & 0.548 & 0.457 & ns & -17.614 & -0.009 & ns & -18.434 & -0.003 & $\mathrm{~ns}$ \\
\hline Tunisia & 17.909 & 0.005 & ns & -16.712 & -0.012 & ns & 16.909 & 0.007 & ns & 16.020 & 0.012 & ns & -0.741 & -0.587 & ns & 1.824 & 1.428 & $\mathrm{~ns}$ \\
\hline Uganda & -0.251 & -0.259 & ns & 0.258 & 0.268 & ns & 18.222 & -0.010 & ns & -0.144 & -0.149 & ns & 0.356 & 0.370 & ns & -18.434 & -0.004 & ns \\
\hline Zambia & 0.952 & 0.833 & ns & -0.839 & -0.912 & ns & -0.656 & -0.746 & ns & -0.550 & -0.626 & ns & -0.741 & -0.806 & ns & -0.478 & -0.414 & ns \\
\hline Zimbabwe & 1.289 & 1.563 & ns & 0.9520 & 1.449 & ns & -0.908 & -1.508 & ns & -0.298 & -0.499 & ns & -0.837 & -1.343 & ns & -1.576 & -1.440 & $\mathrm{~ns}$ \\
\hline Intercept & 0.656 & 1.994 & $*$ & 0.146 & 0.468 & ns & 0.656 & 1.994 & * & 0.550 & 1.696 & ns & 0.048 & 0.156 & ns & -1.131 & -3.111 & * \\
\hline
\end{tabular}

Countries with at least three respondents were included in the analysis (sample size threshold considered). Malawi, Morocco, Seychelles, DRC, Central Republic of Africa, Rwanda, Mali, Reunion, Madagascar, Mauritius, Botswana and Comoros were not included in the analysis. Regions $\left(\chi^{2}=12.223, \mathrm{df}=4, p=0.016\right)$; Countries $\left(\chi^{2}=39.916, \mathrm{df}=18, p=0.002\right)$. ${ }^{\mathrm{a}} \mathrm{MAT}=$ Male Annihilation Technique, ${ }^{\mathrm{b}}$ SIT $=$ Sterile Insect Technique, ${ }^{*}$ indicates a significant difference and "ns" indicates no significant difference at $p=0.05$. 


\subsection{The Level of Fruit Fly IPM Technology Integration and Use in Africa}

The combined application of different strategies varies between regions, countries and locations. In our survey, the most common combinations were: 1 / field sanitation + protein bait spray + MAT or 2/field sanitation + protein bait + biopesticides + MAT + parasitoid releases. In some cases, the application of a single technology has been dominant but at relatively low frequencies (Figure 5). Parasitoid releases were found to be widely used as IPM tactics in Cameroon (Figure 5).

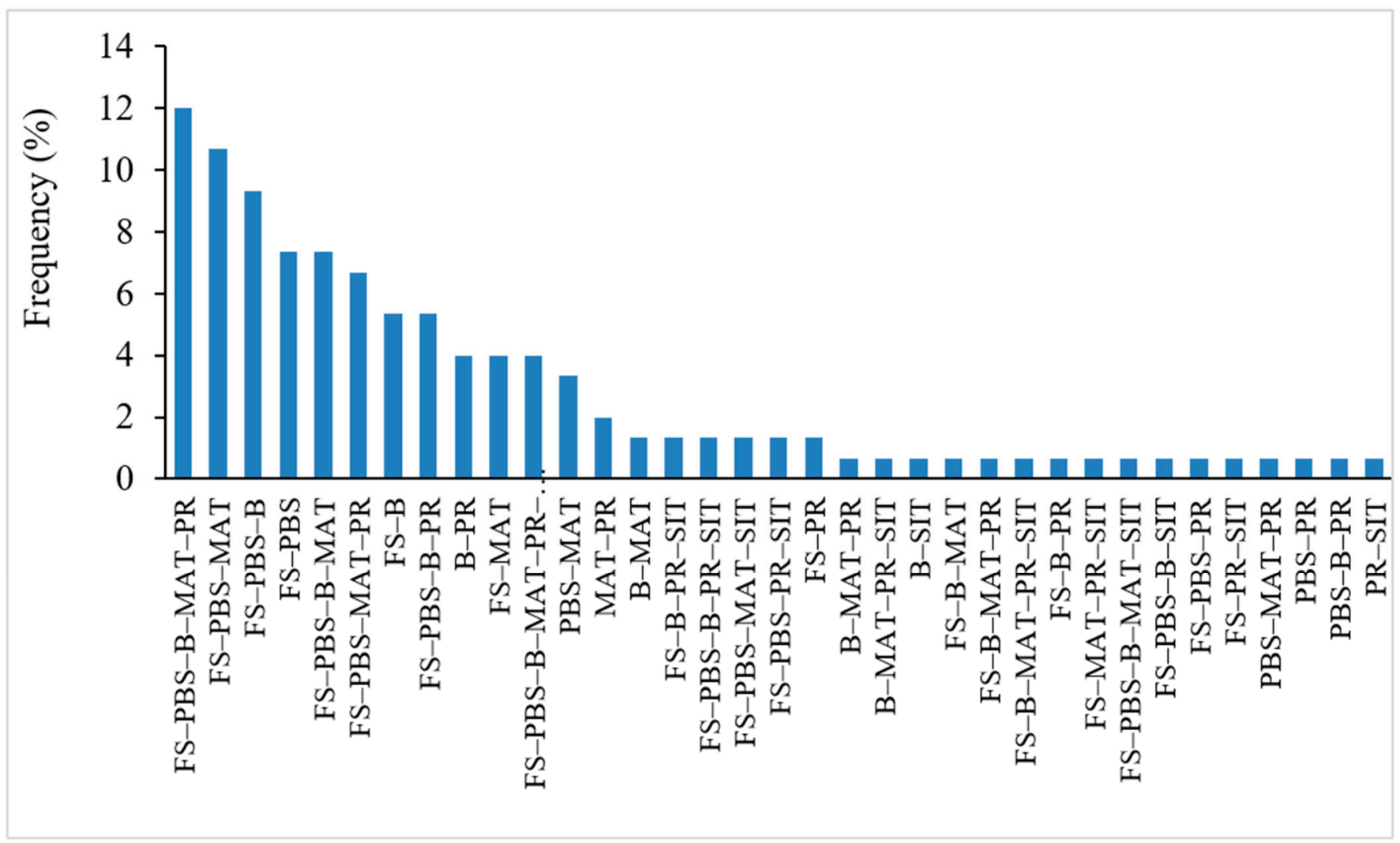

Figure 5. The most common fruit fly IPM combinations in Africa. Note: FS = Field sanitation, MAT $=$ Male Annihilation Technique, PBS = Protein bait spray, B = Biopesticides, PR = Parasitoid release, $\mathrm{SIT}=$ Sterile Insect Technique.

In Western Africa, field sanitation + protein bait spray + biopesticide is the most common IPM combination, followed by field sanitation + protein bait spray + MAT and biopesticides + parasitoid release (Figure 6). In Central Africa, the IPM combination was dominated by field sanitation + protein bait spray (Figure 6). In Eastern Africa, field sanitation + protein bait spray + biopesticide + MAT + parasitoid release was commonly implemented (Figure 6). In Southern Africa, field sanitation + protein bait spray + biopesticide + MAT + parasitoid release and field sanitation + protein bait spray + MAT use were common (Figure 6). 


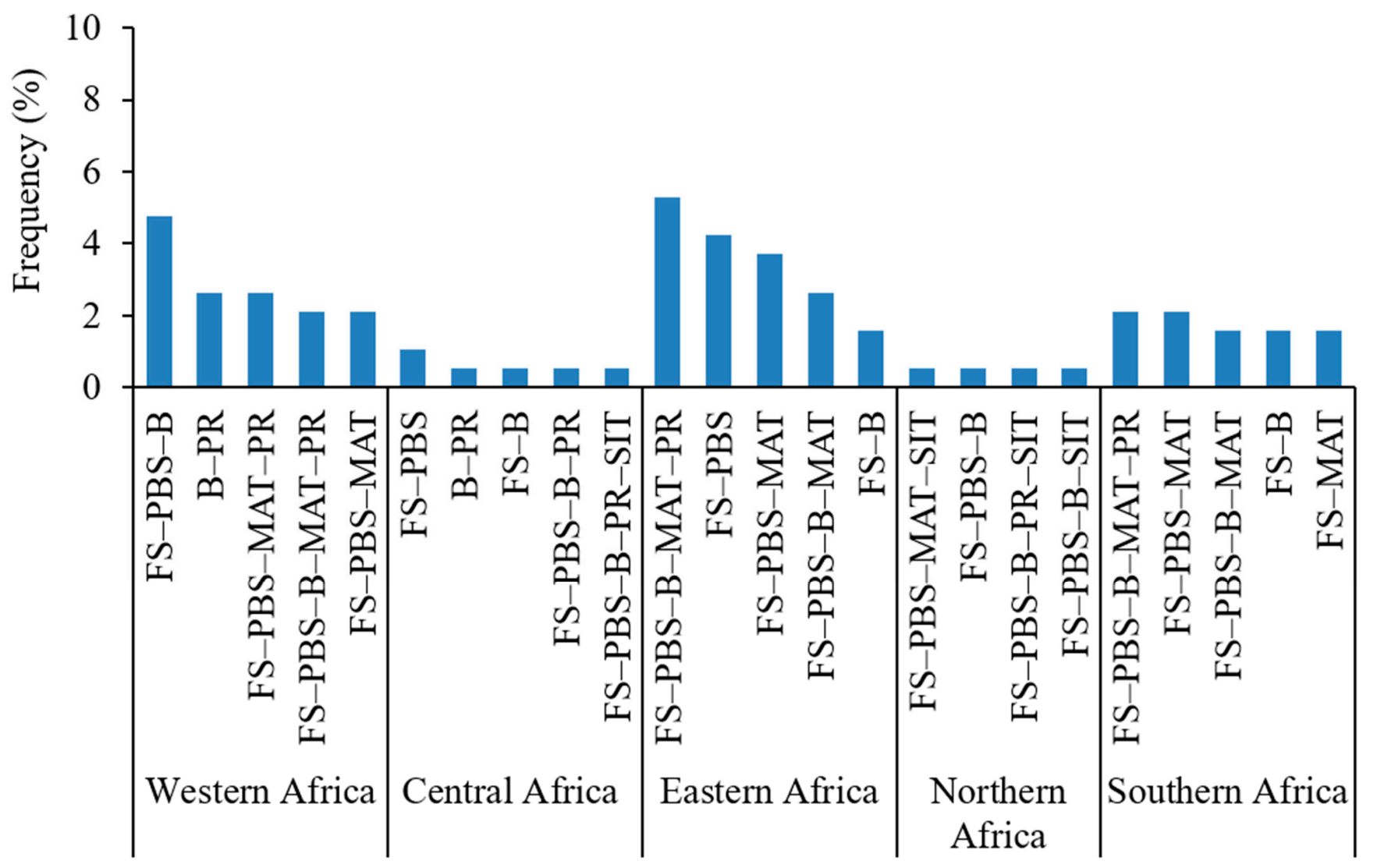

Figure 6. The five most applied fruit fly IPM combinations across different regions of Africa. Note: FS $=$ Field sanitation, MAT = Male Annihilation Technique, PBS = Protein bait spray, $\mathrm{B}=$ Biopesticides, $\mathrm{PR}=$ Parasitoid release, $\mathrm{SIT}=$ Sterile Insect Technique.

\subsection{Number of Beneficiaries from Fruit Fly IPM in Africa}

The proportion of the fruit fly IPM beneficiaries across Africa is illustrated in Figure 7. According to our survey, a total of 101.0 million people were reported to have benefitted from fruit fly IPM interventions across the 30 African countries surveyed. However, there was a significant difference in beneficiaries between regions $(p<0.003)$ and countries $(p<0.001 \%)$. The regions with the highest number of reported beneficiaries from the fruit fly IPM interventions include Eastern Africa (50.2 million), followed by Western Africa (17.7 million), Central Africa (11.7 million), Northern Africa (11.0 million) and Southern Africa (10.4 million) (Figure 7). Compared to Eastern Africa, Southern Africa had fewer beneficiaries of MAT, biopesticides, protein bait spray and parasitoid releases. However, the number of field sanitation and SIT beneficiaries in these two regions is not significantly different (Table 2). Notably, parasitoid releases and the application of biopesticides have significantly benefitted more people in Western and Central Africa than in Southern Africa (Table 2). 




Figure 7. Sunburst chart showing the number of beneficiaries according to IPM technologies per region. The figures in the inner pie chart indicate the total number of beneficiaries regionally. Note: RW = Rwanda, UG = Uganda, SD =Sudan, ET = Ethiopia, KN = Kenya, TZ = Tanzania, $\mathrm{MD}=$ Madagascar, $\mathrm{CO}=$ Comoros, $\mathrm{RE}=$ Reunion, $\mathrm{SY}=$ Seychelles, $\mathrm{MR}=$ Mauritius, $\mathrm{SN}=$ Senegal, $\mathrm{ML}=$ Mali, $\mathrm{CI}=$ Côte d'Ivoire, $\mathrm{BK}=$ Burkina Faso, $\mathrm{GH}=$ Ghana, $\mathrm{TG}=$ Togo, BN = Benin, NG = Nigeria, $\mathrm{MA}=$ Malawi, $\mathrm{ZA}=$ Zambia, $\mathrm{ZM}=$ Zimbabwe, $\mathrm{MZ}=$ Mozambique, $\mathrm{BT}=$ Botswana, $\mathrm{SA}=$ South Africa, $\mathrm{CM}=$ Cameroon, DRC $=$ Democratic Republic of Congo, CAR = Central Africa Republic, $\mathrm{MO}=$ Morocco, $\mathrm{TN}=$ Tunisia .

The numbers of beneficiaries of fruit fly IPM technologies across the surveyed countries are illustrated in Figure 8. The statistical analysis using Kenya as a model country shows that the number of beneficiaries applying field sanitation in addition to other methods was significantly lower in Cameroon, Ghana, Mozambique, Nigeria, Togo, Uganda and Zambia (Table 3). The number of beneficiaries applying MAT in addition to other methods in Burkina, Ethiopia, Mozambique and Uganda was low compared to Kenya. Ghana, Mozambique, Nigeria, Togo, Zambia and Zimbabwe did not benefit from biopesticide use compared to Kenya. Kenya had more beneficiaries applying protein bait spray in addition to other tools than their counterparts in Cameroon, Nigeria, Zambia and Zimbabwe (Table 3). Beneficiaries from Burkina Faso, Cote D'Ivoire, Nigeria, Togo, Zambia, and Zimbabwe lagged behind Kenya in parasitoid releases. A similar trend was observed for the sterile male technique (Table 3). 
Table 2. Comparison of the number of beneficiaries of fruit fly IPM technologies between African regions.

\begin{tabular}{|c|c|c|c|c|c|c|c|c|c|c|c|c|c|c|c|c|c|c|}
\hline & \multicolumn{18}{|c|}{ Fruit Fly IPM Technologies } \\
\hline & \multicolumn{3}{|c|}{ Field Sanitation } & \multicolumn{3}{|c|}{ a MAT } & \multicolumn{3}{|c|}{ Biopesticides } & \multicolumn{3}{|c|}{ Protein Bait Spray } & \multicolumn{3}{|c|}{ Parasitoid Release } & \multicolumn{3}{|c|}{ b SIT } \\
\hline & Estimates & Z Value & & Estimates & Z Value & & Estimates & Z Value & & Estimates & Z Value & & Estimates & Z Value & & Estimates & Z Value & \\
\hline $\begin{array}{c}\text { Central Africa-Eastern } \\
\text { Africa }\end{array}$ & 1.092 & 1.664 & ns & 0.412 & 0.436 & ns & 0.088 & 0.130 & ns & 1.028 & 1.55 & ns & -0.354 & -0.537 & ns & -2.397 & -1.979 & ns \\
\hline $\begin{array}{c}\text { Northern } \\
\text { Africa-Eastern Africa }\end{array}$ & -1.252 & -1.155 & ns & -0.834 & -0.445 & ns & -1.432 & -1.149 & ns & -1.238 & -1.157 & ns & -0.712 & -0.424 & ns & -0.095 & -0.078 & ns \\
\hline $\begin{array}{c}\text { Southern } \\
\text { Africa-Eastern Africa }\end{array}$ & -1.159 & -2.875 & * & -1.428 & -2.875 & * & 0.513 & -4.393 & $* * *$ & -1.420 & -3.106 & * & -3.015 & -5.322 & $* * *$ & -1.927 & -2.283 & ns \\
\hline $\begin{array}{c}\text { Western } \\
\text { Africa-Eastern Africa }\end{array}$ & -0.666 & -1.668 & ns & -0.473 & -0.966 & ns & -0.571 & -1.265 & ns & -0.282 & -0.657 & ns & -0.727 & -1.631 & ns & -3.045 & 0.023 & * \\
\hline $\begin{array}{c}\text { Northern } \\
\text { Africa-Central Africa }\end{array}$ & -0.160 & -0.132 & ns & -0.422 & -0.208 & ns & -1.288 & -0.936 & ns & 0.857 & 0.704 & ns & -0.359 & -0.205 & ns & 2.303 & 1.452 & ns \\
\hline $\begin{array}{c}\text { Southern } \\
\text { Africa-Central Africa }\end{array}$ & -0.067 & -0.098 & ns & -1.016 & -1.039 & ns & -1.826 & -2.930 & * & 0.675 & 0.915 & ns & -2.661 & -3.533 & $* *$ & 0.470 & 0.354 & ns \\
\hline $\begin{array}{c}\text { Western } \\
\text { Africa-Central Africa }\end{array}$ & 0.426 & 0.619 & ns & -0.061 & -0.061 & ns & -0.163 & -0.222 & ns & 1.813 & 2.517 & ns & -0.373 & -0.560 & ns & -0.286 & -0.181 & ns \\
\hline $\begin{array}{c}\text { Southern } \\
\text { Africa-Northern } \\
\text { Africa }\end{array}$ & 0.093 & 0.084 & ns & -0.594 & -0.323 & ns & -0.803 & -0.627 & ns & -0.182 & -0.165 & ns & -2.303 & -1.340 & ns & -1.833 & -1.381 & ns \\
\hline $\begin{array}{c}\text { Western } \\
\text { Africa-Northern } \\
\text { Africa }\end{array}$ & 0.587 & 0.53 & ns & 0.366 & 0.195 & ns & 0.766 & 0.684 & ns & 0.956 & 0.876 & ns & -0.015 & -0.009 & $\mathrm{~ns}$ & -2.590 & -1.633 & ns \\
\hline $\begin{array}{c}\text { Western } \\
\text { Africa-Southern } \\
\text { Africa }\end{array}$ & 0.494 & 1.086 & ns & 0.955 & 1.742 & ns & 1.568 & 2.930 & * & 1.138 & 2.251 & ns & 2.288 & 3.972 & $* * *$ & -0.758 & -0.571 & ns \\
\hline
\end{tabular}

Number of beneficiaries irrespective of specific IPM technology, Regions $\left(\chi^{2}=44.97, \mathrm{df}=4, p<0.001\right) .{ }^{\text {a }}$ MAT $=$ Male Annihilation Technique, ${ }^{\mathrm{b}}$ SIT $=$ Sterile Insect Technique, ${ }^{*}$ indicates significant difference and "ns" indicates no significant difference at $p=0.05$. 


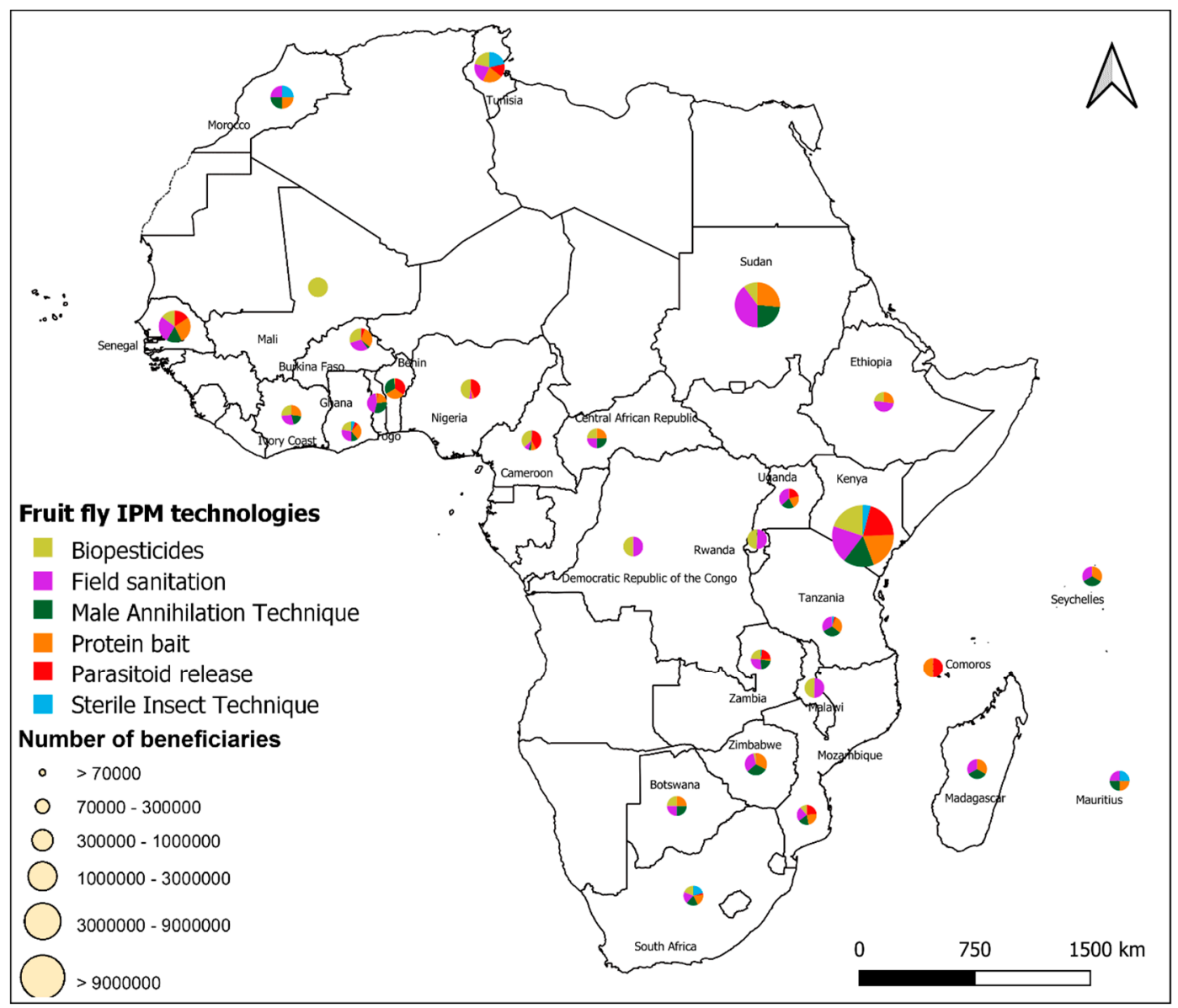

Figure 8. Estimated number of farmers that have benefitted from IPM technological intervention in specific locations across Africa. Note: the size of the pie chart indicates the range of beneficiaries in terms of numbers. Different colours indicate the proportion of beneficiaries for specific fruit fly IPM technology.

3.5. Estimation of the Total Number of Tropical Fruit-Growing Populations and Potential Users of Fruit Fly IPM Technologies

The highest tropical fruit-producing countries were Nigeria, Ethiopia and the Democratic Republic of Congo (DRC) (Figure 9). The potential IPM beneficiaries were estimated at 559 million people, which was highest in Kenya and Sudan (Figure 9). In countries like Kenya, Cameroon, Sudan, Senegal and Cote d'Ivoire, the production of tropical fruits directly correlated with the estimated number of beneficiaries of IPM tactics (Figure 9). Principal component analysis revealed that the estimated number of beneficiaries of fruit fly IPM technologies (101 million) mirrored the estimated number of tropical fruit production population but less so with the total population and the potential number of beneficiaries across the surveyed African countries (Figure 10). 
Table 3. Estimates of the regression parameter based on the negative binomial model for the number of beneficiaries of fruit fly IPM technologies across fruit-growing countries in Africa using Kenya as reference country.

\begin{tabular}{|c|c|c|c|c|c|c|c|c|c|c|c|c|c|c|c|c|c|c|}
\hline \multirow[t]{3}{*}{ Countries } & \multicolumn{18}{|c|}{ Fruit Fly IPM Technologies } \\
\hline & \multicolumn{3}{|c|}{ Field Sanitation } & \multicolumn{3}{|c|}{${ }^{\text {a }}$ MAT } & \multicolumn{3}{|c|}{ Biopesticides } & \multicolumn{3}{|c|}{ Protein Bait Spray } & \multicolumn{3}{|c|}{ Parasitoid Release } & \multicolumn{3}{|c|}{ b SIT } \\
\hline & Estimate & Z Score & & Estimate & Z Score & & Estimate & Z Score & & Estimate & Z Score & & Estimate & Z Score & & Estimate & Z Score & \\
\hline Burkina Faso & -0.493 & -0.826 & ns & -2.322 & -3.418 & $* * *$ & 0.315 & 0.370 & ns & -0.392 & -0.632 & ns & -2.586 & -4.411 & $* * *$ & -2.586 & -4.411 & $* * *$ \\
\hline Cameroon & -1.741 & -2.485 & * & -1.751 & -1.817 & ns & -0.182 & -0.254 & ns & -1.988 & -3.203 & $* *$ & -0.618 & -1.054 & & -0.618 & -1.054 & ns \\
\hline Côte d'Ivoire & -0.571 & -0.816 & ns & 0.861 & 0.538 & ns & -0.375 & -0.485 & ns & - & - & - & -5.582 & -3.844 & $* * *$ & -5.582 & -3.844 & $* * *$ \\
\hline Ethiopia & -1.099 & -1.164 & ns & -5.353 & -3.343 & $* * *$ & -0.715 & -0.440 & ns & - & - & - & - & - & - & - & - & - \\
\hline Ghana & -3.228 & -3.417 & $* * *$ & -3.051 & -1.906 & ns & -3.017 & -2.585 & $* *$ & -1.710 & -1.822 & ns & - & - & - & - & - & - \\
\hline Mozambique & -4.412 & -7.061 & $* * *$ & -4.242 & -5.467 & $* * *$ & -3.710 & -3.179 & $* *$ & -0.751 & -0.478 & ns & - & - & - & - & - & - \\
\hline Nigeria & -4.249 & -3.736 & $* * *$ & - & - & - & -2.307 & -2.382 & * & -4.147 & -5.951 & $* * *$ & -3.972 & -5.147 & $* * *$ & -3.972 & -5.147 & $* * *$ \\
\hline Senegal & 0.347 & 0.527 & ns & -0.217 & -0.320 & ns & -0.355 & -0.556 & ns & - & - & - & - & - & - & - & - & - \\
\hline South Africa & -1.866 & -1.641 & ns & -1.872 & -1.619 & ns & -1.838 & -1.575 & ns & -3.053 & -1.944 & ns & - & - & - & - & - & - \\
\hline Sudan & 0.888 & 1.649 & ns & 0.632 & 1.020 & ns & 0.6439 & 0.755 & ns & -1.874 & -1.659 & ns & -3.279 & -2.259 & * & -3.279 & -2.259 & $*$ \\
\hline Togo & 3.402 & -3.601 & $* * *$ & -3.339 & -2.815 & $* *$ & -5.319 & -3.277 & $* *$ & 1.008 & 1.542 & ns & 5.582 & -3.844 & $* * *$ & -5.582 & -3.844 & $* * *$ \\
\hline Tunisia & -1.387 & -1.220 & ns & - & - & - & -1.359 & 1.1672 & ns & -3.410 & -3.633 & $* * *$ & -5.582 & -3.844 & $* * *$ & -5.582 & -3.844 & $* * *$ \\
\hline Uganda & -3.402 & -3.592 & $* * *$ & -3.967 & -4.116 & $* * *$ & - & - & - & -1.395 & -1.234 & $\mathrm{~ns}$ & -0.977 & -0.673 & $\mathrm{~ns}$ & -0.977 & -0.673 & ns \\
\hline Zambia & -2.640 & -3.493 & $* * *$ & -1.952 & -1.688 & ns & -2.244 & -2.316 & * & -3.970 & -4.230 & $* * *$ & -4.195 & -4.801 & $* * *$ & -4.196 & -4.801 & $* * *$ \\
\hline Zimbabwe & -0.876 & -1.714 & ns & -0.778 & -1.384 & ns & -2.289 & -3.397 & $* * *$ & -4.142 & -4.413 & $* * *$ & -2.181 & -2.079 & * & -2.181 & -2.079 & $*$ \\
\hline Intercept & 12.255 & 40.263 & $* * *$ & 12.255 & 40.263 & $* * *$ & 10.915 & 6.834 & $* * *$ & 13.820 & 8.986 & $* * *$ & 12.542 & 17.961 & ns & 13.820 & 8.986 & $* * *$ \\
\hline
\end{tabular}

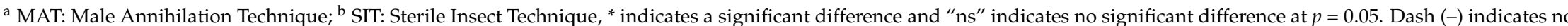
reported beneficiary of technology by the respondents in their respective countries. 


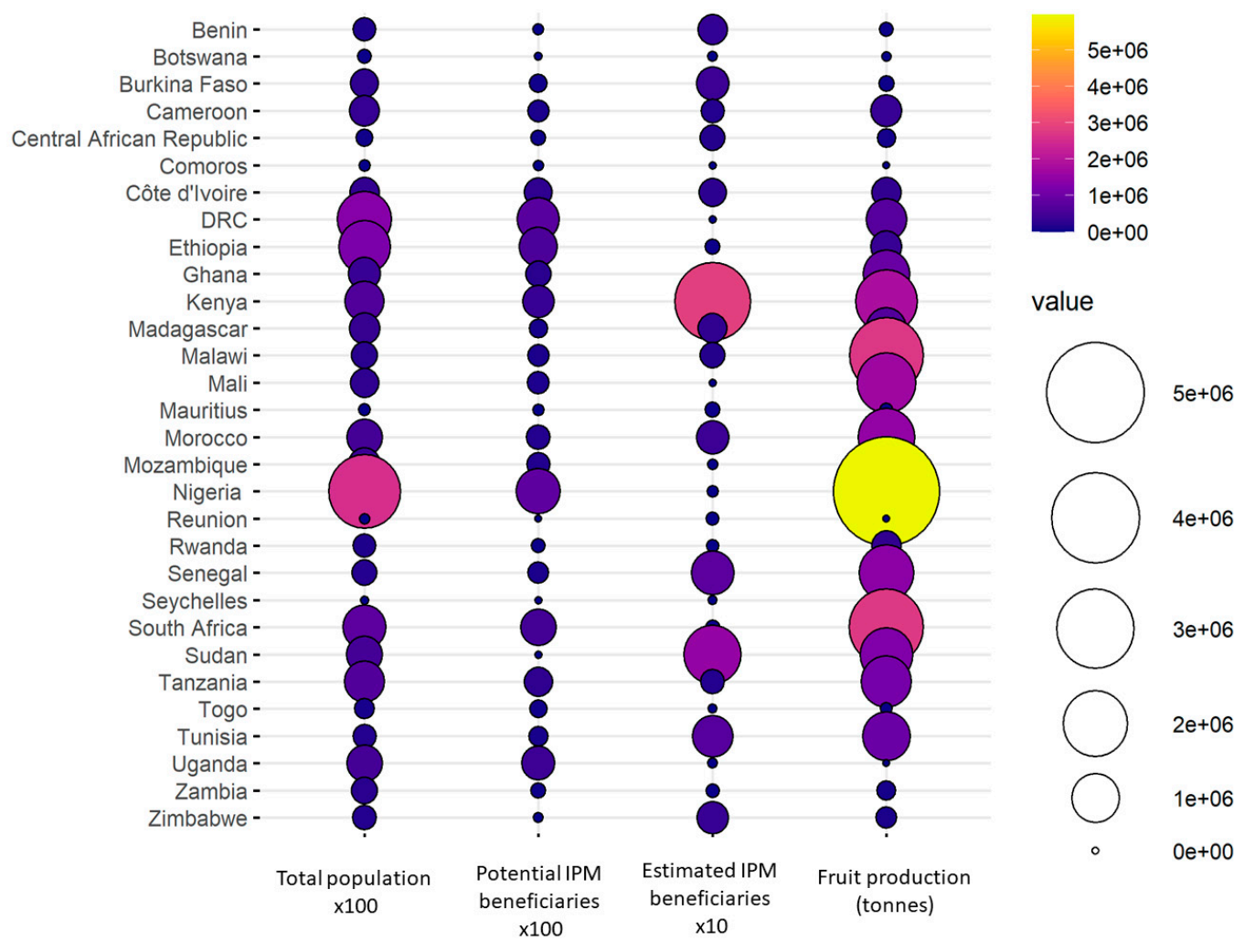

Figure 9. Representation of the total population, potential and estimated beneficiaries and production capacity of fruit-growing countries.

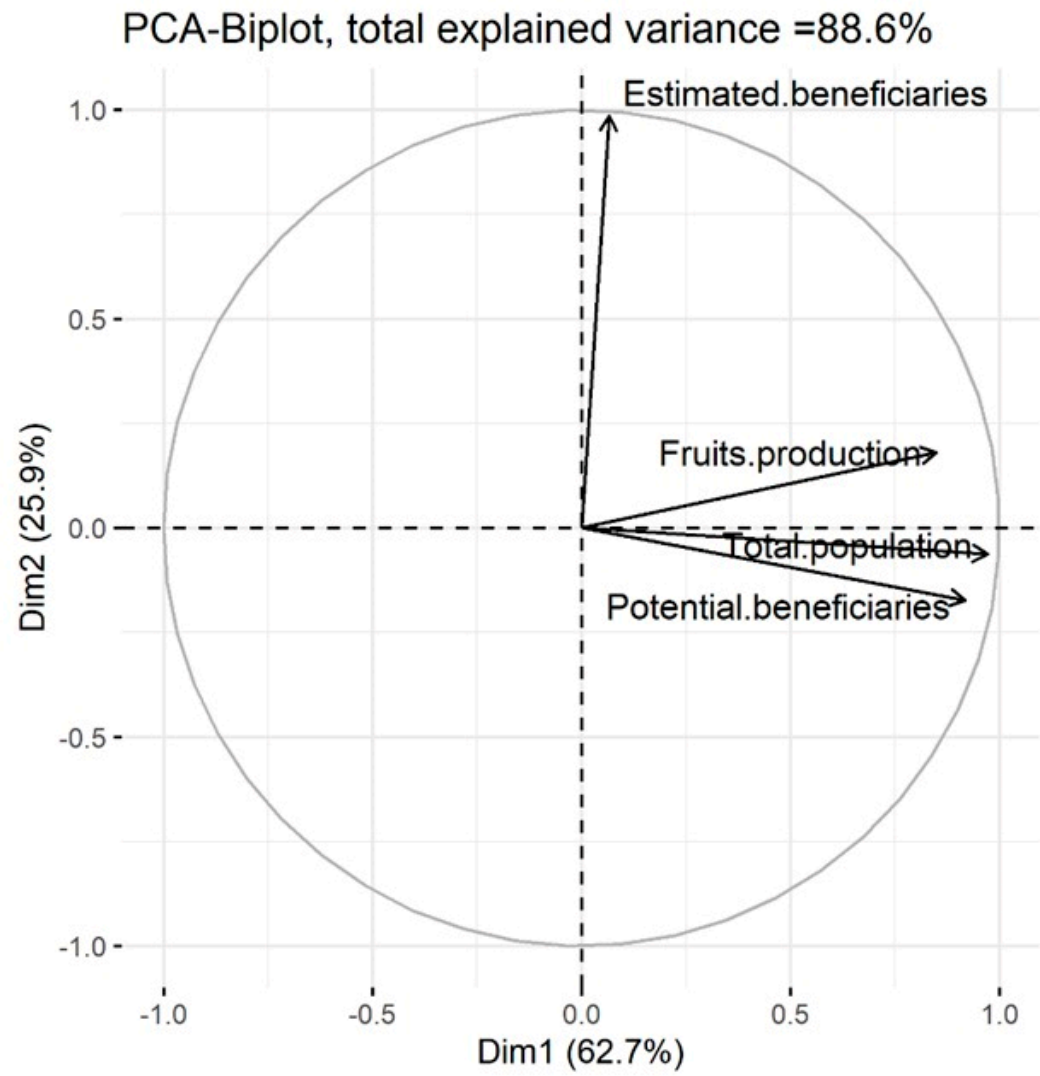

Figure 10. Principal component analysis (PCA) depicting African countries' total population, number of potential IPM beneficiaries, estimated IPM beneficiaries and production capacity of various fruits. 


\subsection{Barriers to the Uptake of IPM Technologies}

The respondents acknowledged challenges to the rapid uptake of fruit fly IPM technologies (Table 4). The topmost challenges cited by respondents from the target regions included the lack of awareness of available IPM technologies, insufficient training and technical support, lack of access to IPM products and limited private sector involvement.

Table 4. Challenges limiting the scaling up of fruit fly IPM technologies in Africa.

\begin{tabular}{cc}
\hline Challenges & Frequency (\%) \\
\hline Farmers are not aware of the available IPM products & 14 \\
Insufficient training and technical support to farmers & 12 \\
Lack of access to the IPM products & 12 \\
Limited private sector involvement & 11 \\
Lack of existing policies for the regulation of IPM options & 10 \\
Limited well-qualified IPM experts & 8 \\
Farmers have low levels of education and literacy & 8 \\
Farmers are resistant to change their habitual management practices & 7 \\
Lack of incentives for products grown using IPM products & 6 \\
IPM is too expensive & 5 \\
IPM is difficult to understand and implement compared with & 3 \\
Rynthetic pesticides & 3 \\
IPM costs are higher than benefits & 1 \\
\hline
\end{tabular}

The barriers to IPM technology uptake varied regionally (Figure 11). Across the regions, the lack of farmers' awareness of the IPM technologies was noted to be a key challenge. In addition, the topmost important challenges in the Western region were insufficient training and technical support to farmers, lack of access to the IPM products and limited private sector involvement (Figure 11). In Eastern and Northern Africa, insufficient training and technical support, lack of access to the IPM products, limited private sector involvement, lack of existing policies for the regulation of IPM options, low levels of education and literacy, and farmers' resistance to change from their habitual management practices were found to be the key barriers to technological uptake (Figure 11). Additionally, the lack of access to the IPM products and limited well-qualified IPM experts were found to be the topmost challenges in Eastern Africa. The lack of incentives for produce grown using IPM technologies and the cost of the IPM tools being higher than the benefits were reported as challenges in Northern Africa (Figure 11). In Central Africa, insufficient training and technical support, lack of access to IPM products, lack of existing policies for the regulation of IPM options and IPM practices being too expensive to implement were the main challenges. In Southern Africa, the topmost challenges were the lack of access to IPM products and limited private sector involvement (Figure 11). 


\section{African regions}

\section{Challenges}

Farmers are not aware of the available IPM products

Insufficient training and technical support to farmers

Limited private sector involvement

Lack of existing policies for the regulation of IPM option

Lack of access to the IPM products

Farmers are resistant to change their habitual management practices

Farmers have low levels of education and literacy

Lack of incentives for produce grown using IPM products

Limited well-qualified IPM experts

IPM costs are higher than benefits

IPM is too expensive

IPM is difficult to understand and implement compared with synthetic pesticides

Registration process is too complicated
Western Northern Central Eastern Southern

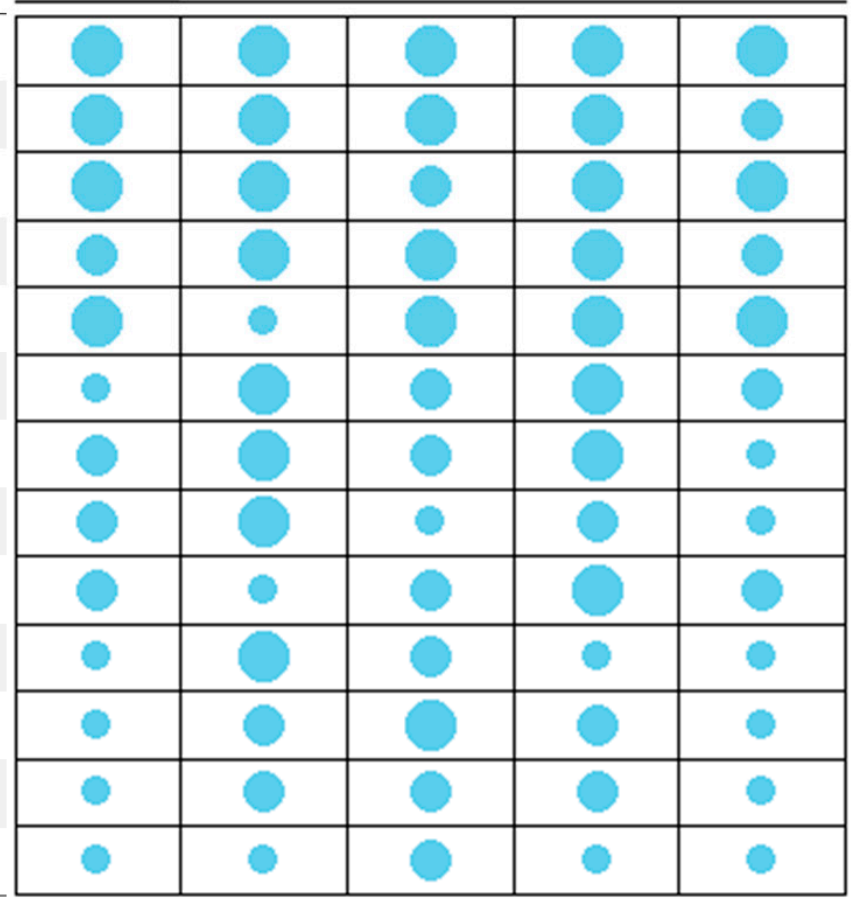

Figure 11. The challenges were sorted based on their veracity using cluster analysis. $3=$ Most pressing challenges, 2 = slightly common challenges, 1 = least common or rare challenges. The size of the balloon plots corresponds to three clusters.

\section{Discussion}

Horticulture is an engine for economic growth, trade expansion and the development of income-generation opportunities. However, the horticulture industry is a highly technical and knowledge-intensive sub-sector, and success is contingent on a myriad of factors, including biotic constraints associated with native (C. cosyra, C. rosa, C. fasciventris, C. quilicii, C. anonae, C. capitata) and invasive fruit flies (B. dorsalis, B. zonata, B. latifrons, Z. cucurbitae). In many countries, producers are largely excluded from lucrative international markets if they cannot meet the production, phytosanitary and quality standards associated with fruit flies [38]. Over the last two decades, innovative strategies of fruit fly pre- and post-harvest management have been developed and widely disseminated and promoted in Africa to increase fruit yield and minimise the reliance on synthetic chemical pesticides that lead to toxic residues, thereby facilitating the compliance with the stringent standards required for the domestic and export markets $[4,11-13,15,22]$. There has been a widespread adoption of various technologies with high returns on investment $[4,9,11-13,22,39]$. Despite the success, there is a general recognition that many relevant agricultural or IPM innovations are not achieving their full potential impact because of beneficiaries' low levels of uptake and adoption $[23,40-44]$.

In the case of the fruit flies, while there is evidence of a high rate of IPM uptake, information on the actual number of beneficiaries across countries and the barriers to scaling up the innovations are not well documented. This is crucial to increase the impact in the transition towards the sustainability and equity required for fruit fly management across the African continent.

The current survey revealed that over the last two decades, the penetration of the fruit fly technologies across Africa has been low in some countries and high in others, benefitting 
only 101 million people, with the potential to reach 559 million tropical fruit producing households. This is perhaps not surprising, given that several programmes and projects in Africa on fruit fly management were designed on the premise that they should reach a large number of beneficiaries at scale $[19,30,31]$. However, the percentage of respondents from the northern region of Africa was much lower compared to that of other regions, which necessarily impacted the results obtained. Consequently, the low number of respondents from this region may have contributed to the lower beneficiary numbers reported.

Nevertheless, the uptake of the different fruit fly technologies differed significantly across the continent. Consequently, technology combinations within the content of IPM varied considerably. Out of the six fruit fly IPM components being disseminated, field sanitation remains the most mentioned management practice across the continent. A poorly managed or abandoned orchard can result in a high population build-up of fruit flies. The African fruit fly programme implemented in Central, Eastern, Western and Southern Africa encouraged end-users of its technologies to systematically manage their orchard within the context of the existing socio-cultural farm management practices, including field sanitation [19]. Indeed, orchard sanitation, which entails the collection and destruction of all infested fruits found on the tree and the ground, can contribute to the reduction of fruit fly populations in the orchard [45-49]. Therefore, it is not surprising that several farmers adopted this management practice. The collected fruits are destroyed by either burning, burying or putting them in tied black plastic bags and exposing them to the heat of the sun for a few days until the fruits are rotten and all the maggots in the bags are dead [49]. Orchard sanitation does not require input; it relies mainly on farmer awareness, willingness, and household labour [45-49].

According to the survey, protein bait sprays were the next most widely used technology. Fruit fly suppression is mainly based on the use of food baits (hydrolysed proteins or their ammonium mimics) combined with a killing agent (an insecticide) applied in localised spots. This method targets adult flies, mainly females, and aims at attracting and killing them before they infest fruits (lay eggs into the fruits). The protein bait attractants have been used for mass trapping, whereby the fruit flies from a distance are attracted to the application spot (could be the tree trunk or a portion of the tree canopy with or without fruits or a support such as straw plugs, as used in Morocco), where the flies feed on the bait, ingest the pesticide and die $[7,23,40,49-51]$. Several baits are commercially available in Eastern, Central, Northern, Western and Southern Africa, such as NuLure ${ }^{\circledR}$, Buminal $^{\circledR}$, and GF-120 (Success $\left.{ }^{\circledR}\right)$. A major problem with the baits listed above in Africa is that they have to be imported from foreign sources, thus making them expensive and inaccessible to a large number of fruit growers [19,52]. Most recently, a local protein bait based on waste brewer's yeast was developed by the private sector in Kenya [52]. The product was recently registered and commercialised as Fruit Fly Mania ${ }^{\circledR}$ and retailed at $70 \%$ less than the cost of imported commercial products. The fruit fly Protein Bait Facility, which is the first of its kind in sub-Saharan Africa and based in Makuyu (Kenya), has a production capacity of 2000 litres per day, which is enough to meet the demands of the producers affected by fruit flies on the continent and should therefore enhance their availability (https://www.biovision.ch/en/news/fruit--fly--bait/, accessed on 5 January 2022).

In this study, biopesticides and the male annihilation technique (MAT) were widely used across Africa and corroborate earlier observations of the wide application of these control tools $[7,19,53,54]$. Several biopesticides based on bacteria (Bacillus thurungiensis), Spinosad, Azadrachtin and fungi (Beauveria bassiana and Metarhizium anisopliae) have been registered in many African countries [6,49,55]. For instance, the biopesticide commonly used for fruit fly control is fungus-based (Mazao Campaign ${ }^{\circledR}$ ) and targets both adult and pupating larval stages of fruit flies in the soil [55].

The male annihilation technique (MAT) is a control strategy that involves the deployment of high-density trapping stations consisting of a male attractant combined with an insecticide [54]. The aim is to reduce male fruit fly populations to low levels so that mating does not occur (in case of eradication) or is reduced to low levels (in the case of suppres- 
sion). Several male attractants, such as methyl eugenol, can be used with an appropriate toxicant $[7,19,51,54]$. Methyl eugenol is one of the few common attractants registered in Africa. The smooth transfer of innovations and meaningful impact at scale demands that the research for development teams must engage with regulatory authorities for product commercialisation [56]. Currently, a lengthy regulatory process in most countries in Eastern, Central, Western and Southern Africa prior to commercialisation constrains the product availability to beneficiary end-users, which is a common phenomenon with the biopesticide and MAT and partly explains the low penetration of these technologies compared to field sanitation. To the best of our knowledge, there is only one company producing the fruit fly biopesticide (Mazao Campaign ${ }^{\circledR}$ ) in Africa, based in Kenya. It is encouraging to see developments in the harmonisation of regulations regarding biopesticide registration in Eastern and Western Africa [57]. However, there is a need to address supply chain requirements and expand distribution channels for these products for maximum benefit in fruit fly control. Kenya and Senegal are hubs for biopesticides and MAT, with several producing companies. Our study, therefore, suggests a higher private sector involvement and support for the harmonisation of the registration, to expand fruit fly control products in Africa.

The respondents reported that fruit fly parasitoids were a key component of the IPM package in Central, Eastern, Western and Southern Africa. In Kenya, all the indigenous parasitoid species (e.g., Psyttalia cosyrae (Wilkinson), Psyttalia phaeostigma (Wilkinson) (both Hymenoptera: Braconidae), Tetrastichus giffardii Silvestri (Hymenoptera: Eulophidae)) that were evaluated for their performance against $B$. dorsalis were not able to form new associations with this pest due to its strong immune response [58,59]. This necessitated the importation and subsequent release of efficient coevolved natural enemies capable of controlling B. dorsalis. In this regard, two opiine koinobiont endoparasitoids, Fopius arisanus (Sonan) and Diachasmimorpha longicaudata (Ashmead) (both Hymenoptera: Braconidae), were introduced from Hawaii (USA), where they have been used for one of the most outstanding classical biological controls ever undertaken against fruit flies in Hawaii [60,61], French Polynesia [62] and Senegal [63]. Following all the necessary laboratory assessments, which proved the efficacy of these parasitoids against the target pest [64,65], both F. arisanus and D. longicaudata were released in Kenya, while the former was successively released in several other African countries (Tanzania, Benin, Senegal, Cameroun, Togo, Zimbabwe, Zambia, Namibia, Ethiopia, Uganda). The post-release assessment of the colonisation of F. arisanus carried out in almost all of these countries indicated that the parasitoid has established a high rate of parasitism. For example, on the Kenyan coast, up to 40-46.5\% parasitism was reported on B. dorsalis [66-68]. The evident contribution of F. arisanus in the suppression of $B$. dorsalis has resulted in considerable socioeconomic benefits to fruit growers. The impact of classical biological control is usually not perceptible to the growers, since the natural enemies are usually less visible. The low rating from the survey could be associated with its lesser visibility.

Historically viewed as an eradication technique, SIT is now being promoted as a control technique within the context of area-wide management [9,50]. The low scoring with regard to SIT is not surprising, given that this method is currently only successfully practised in the Hex River Valley, Western Cape Province, in South Africa, targeting C. capitata [69], and plans are underway to implement SIT targeting the same pest in Morocco [6]. The Hex River Valley programme clearly demonstrated the need to expand its application across isolated areas in Africa for fruit fly control. This can create areas of low fruit fly prevalence and, if complemented with effective IPM measures, can lead to fruit fly free areas and provide access to international fruit markets without the need for fruit fly trade restrictions [70].

According to the survey, Eastern Africa and Western Africa were observed to be the leading regions in terms of the fruit fly technological uptake out of the over 101 million people benefitting across the 30 African countries. In Eastern and Western Africa, most of the project interventions were largely carried out through area-wide management approaches [29,52,70-73]. The spillover of the area-wide management approaches may 
have benefitted nontarget households and contributed to a high number of beneficiaries in the region $[74,75]$. Nevertheless, whilst most fruit fly projects have concentrated in Eastern and Western Africa, it is encouraging to see that IDRC/ACIAR has approved funding to transfer these proven fruit fly IPM technologies to Southern African countries like Malawi, Mozambique, Zambia and Zimbabwe (https:/ / www.idrc.ca/en/research-inaction/implementing-sustainable-pest-management-program-combat-fruit-flies, accessed on 5 January 2022), and several operational activities are similarly underway in Northern Africa [6,7]. This initiative should significantly boost the number of beneficiaries from these regions. It should also be noted that other management methods, such as the female mass trapping that relies on putrescine, trimethylamine and ammonium acetate (PTA), were not included in the list of technologies in the survey, and this control method is commonly used in Egypt, Tunisia and Morocco [6,8,76,77]. This is a significant caveat to the reported beneficiary numbers from Northern Africa. The same is true for the ant technology, which has been used by some growers in Western Africa [78,79], but this was not captured in the list of technologies. The overall number of beneficiaries reported in this study would probably be significantly higher if all available fruit fly technologies used in the various regions across Africa were captured in the survey, which should be considered in future investigations. Likewise, mass trapping is the most used IPM technology in Tunisia, Morocco and Egypt against Medfly.

Despite relentless efforts to disseminate and promote the fruit fly IPM package, the demand for the technology outstrips the supply of technological innovation and ultimately adoption. Our analysis revealed a considerable deficit between actual and potential beneficiaries' populations. The potential beneficiary populations living in tropical fruit-growing areas in the selected 30 African countries is estimated at 559 million. According to our study, only $19.1 \%$ of the potential beneficiaries in the selected countries have been reached. Although figures should be interpreted carefully, there is a clear indication of a good penetration in Benin, Kenya, Senegal, Zimbabwe, Tunisia, Sudan, Burkina Faso and a severe deficit in Ethiopia, Malawi, Mali, Nigeria, Rwanda and other countries. Compared to the other countries, there have been few fruit fly IPM initiatives in these countries, and the lack of capacity and access to pre- and post-harvest technologies may account for the low penetration. These drawbacks have contributed to recurrent fruit rejections and bans in lucrative export markets, with severe socioeconomic impacts [14].

Indeed, the experts in this survey attributed the slow uptake of the fruit fly IPM to several challenges. Key among them are the lack of awareness of available IPM products, insufficient training and technical support to farmers and the cost and limited access to the technological packages compared to synthetic pesticides. In general, conventional pesticides are widely used by fruit and vegetable producers for fruit fly management. This could be explained by the fact that the technical knowledge required by producers to achieve pest control with a synthetic pesticide is, therefore, lower than for other management strategies, such as IPM [80,81]. Additionally, few private sector companies are engaged in producing and distributing the fruit fly IPM products, and supply chains would need to expand rapidly to decrease the cost of the technologies and increase the access to producers.

The awareness of the enormity of the fruit fly problem in Africa has created interest in management. Nevertheless, the survey still showed a low level of education and literacy on the IPM technologies and warrants the need for capacity development, especially to growers, plant protection practitioners, policymakers and quarantine officers on how to effectively apply the knowledge for fruit fly suppression [44]. Deguine et al. [82] noted that IPM is knowledge-intensive and identified farmers' deficient ecological literacy and incomplete understanding of its constituent processes as a key factor hampering the uptake of IPM. The fruit fly IPM consists of a menu of options for farmers to deploy, and selecting the right combinations could be challenging to beneficiary smallholders. Smallholder farmers also operate in heterogeneous farm settings and thus have diverse needs [83,84]. Hence, group-based learning and decision-making processes should fast-track technological uptake [85], which should be explored in the future to enhance the uptake of the right 
combinations of tactics. Overall, it is encouraging to see many private sector interests in Eastern, Central, Western and Southern Africa in the commercialisation and registration of fruit fly IPM products, which should eventually lower the fixed cost of adoption as the technology is widely taken up.

The reported numbers of beneficiaries may not accurately reflect the actual beneficiaries and, at best, are somewhat conservative. For instance, while field sanitation may directly benefit the farmer who practises it, classical biological control with parasitoids and MAT has a landscape effect, benefitting a much larger area than at the individual farm level. The survey did not include other IPM tools such as female fruit fly mass trapping and ant technology. The sample size, while still reasonable, can be expanded, and a wider geographical coverage across Africa is warranted. A more robust approach to estimating the total number of beneficiaries using mathematical and spatial econometric models and artificial intelligence should provide more information on the fruit fly IPM technology beneficiaries across Africa.

\section{Conclusions}

The survey provided an overview of the beneficiaries of fruit fly IPM programmes after two decades of research to improve the management of these pests in Africa. A total of 101 million have benefitted from IPM technologies out of a total of 559 million fruit producers. There is a clear scope to reach more beneficiaries and to improve the IPM adoption in its true significance: monitoring of fruit fly levels + combination of several methods, especially in the central, southern and northern regions of Africa. A comprehensive scaling strategy of the fruit fly IPM is recommended based on interrelated pathways of engaging and influencing policy, product commercialisation and delivery, and knowledge exchange and partnerships which should further strengthen technological uptake. We recommend strategic partnerships with different actors to help the scaling process to reach more beneficiaries and have a greater impact.

Author Contributions: Conceptualization, S.N. (Saliou Niassy), S.M. and S.E.; methodology, S.N. (Saliou Niassy) and E.R.O.; software, E.R.O. and E.K.; validation, S.N. (Saliou Niassy) and E.R.O.; formal analysis, E.R.O.; investigation, S.N (Shepard Ndlela), E.R.O. and S.N. (Saliou Niassy); resources, S.N. (Saliou Niassy), H.T., S.M. and S.E.; data curation, E.R.O.; writing—original draft preparation, S.N. (Saliou Niassy) and E.R.O.; writing-review and editing, S.N. (Shepard Ndlela), B.M., E.R.O., H.T., S.N; visualization, E.R.O. and E.K.; super-vision, S.N. (Shepard Ndlela), H.T., S.M. and S.E.; project administration, S.N. (Shepard Ndlela) and S.E.; funding acquisition, S.E. All authors have read and agreed to the published version of the manuscript.

Funding: This research received financial support from the International Development Research Centre (IDRC) funded project Alien invasive fruit flies in Southern Africa: Implementation of a sustainable IPM programme to combat their menaces. Authors of this manuscript are grateful to the UK's Foreign, Commonwealth \& Development Office (FCDO); the Swedish International Development Cooperation Agency (Sida); the Swiss Agency for Development and Cooperation (SDC); the Federal Democratic Republic of Ethiopia; and the Government of the Republic of Kenya.

Institutional Review Board Statement: Not applicable.

Informed Consent Statement: Not applicable.

Data Availability Statement: Datasets related to this research are available from the corresponding author upon reasonable request.

Acknowledgments: The authors acknowledge various donors, programmes and projects implementing fruit fly control activities in Africa, including the icipe-led African Fruit Fly Programme (AFFP), the Belgian Development Cooperation fruit fly projects in Tanzania and Mozambique, the West African fruit fly initiative and various International Atomic Energy Agency (IAEA) Coordinated Research Programmes and sterile insect technique (SIT) projects in Eastern, Northern and Western Africa. All these projects have been generously supported by the German Federal Ministry for Economic Cooperation and Development, implemented by the Deutsche Gesellschaft für Internationale Zusammenarbeit (GIZ), the International Fund for Agricultural Development (IFAD), 
the Biovision Foundation, Belgian Directorate-General for Development Cooperation (DGDC), the Belgian Science Policy (BELSPO), ERAfrica, IAEA, the UK Foreign Commonwealth and Development Office (FCDO) (formerly the Department for International Development, DFID), the United States Agency for International Development (USAID) and the United States Department of Agriculture, Foreign Agriculture Service (USDA-FAS), in coordination with the USDA Animal and Plant Health Inspection Service (UDA-APHIS), the Food and Agriculture Organization (FAO) of the UN, the Dutch Programme for Cooperation with International Institutions (Netherland-SII), the European Union (EU) Australian Centre for International Agricultural Research (ACIAR), the Canada International Development Research Center (IDRC), the European Union (EU) and several private sector partners. The views expressed herein do not necessarily reflect the official opinion of the donors. The authors are also grateful to all respondents, in their respective countries and institution, who took the time to fill in the questionnaire and provide relevant information for this study. We are grateful to experts affiliated with the African Association of Insect Scientists (AAIS), the Inter-African Phytosanitary Council of the African Union (IAPSC-AU), the Centre for Coordination of Agricultural Research and Development for Southern Africa (CCARDESA), the West and Central African Council for Agricultural Research and Development (CORAF), the North African Sub-Regional Research Organization (NASRO), the Association for Strengthening Agricultural Research in Eastern and Central Africa (ASARECA) and the Tephritid Workers Database.

Conflicts of Interest: The authors declare no conflict of interest. The funders had no role in the design of the study, in the collection, analyses, or interpretation of data, in the writing of the manuscript, or in the decision to publish the results.

\section{References}

1. FAO. The Future of Food and Agriculture-Trends and Challenges; FAO: Rome, Italy, 2017; pp. 1-180.

2. Weinberger, K.; Lumpkin, T.A. Diversification into horticulture and poverty reduction: A research agenda. World Dev. 2007, 35, 1464-1480. [CrossRef]

3. Vayssières, J.F.; Sinzogan, A.; Adandonon, A.; Rey, J.Y.; Dieng, E.O.; Camara, K.; Sangarè, M.; Ouedraogo, S.; Sidibé, A.; Keita, Y.; et al. Annual population dynamics of mango fruit flies (Diptera: Tephritidae) in West Africa: Socio-economic aspects, host phenology and implications for management. Fruits 2014, 69, 207-222. [CrossRef]

4. Badii, K.B.; Billah, M.K.; Afreh-Nuamah, K.; Obeng-Ofori, D.; Nyarko, G. Review of the pest status, economic impact and management of fruit-infesting flies (Diptera: Tephritidae) in Africa. Afr. J. Agric. Res. 2015, 10, 1488-1498. [CrossRef]

5. White, I.M.; Elson-Harris, M.M. Fruit Flies of Economic Significance: Their Identification and Bionomics; CAB International: Wallingford, UK, 1992.

6. Rachid, E.; Mazih, A. Current status and future prospects of Ceratitis capitata Wiedemann (Diptera: Tephritidae) control in Morocco. J. Entomol. 2018, 15, 47-55. [CrossRef]

7. Boulahia-Kheder, S. Review on major fruit flies (Diptera: Tephritidae) in North Africa: Bio-ecological traits and future trends. Crop. Prot. 2021, 140, 105416. [CrossRef]

8. Vayssières, J.F.; Korie, S.; Coulibaly, O.; Van Melle, C.; Temple, L.; Arinloye, D. The mango tree in central and northern Benin damage caused by fruit flies (Diptera Tephritidae) and computation of economic injury level. Fruits 2009, 64, 207-220. [CrossRef]

9. Barnes, B.N.; Venter, J.H. The South African fruit fly action plan: Area-wide suppression and exotic species surveillance. In Fruit Flies of Economic Importance: From Basic to Applied Knowledge, Proceedings of the 7th International Symposium on Fruit Flies of Economic Importance, Salvador, Brazil, 10-15 September 2006; IAEA: Vienna, Austria; pp. 271-283.

10. José, L.; Cugala, D.; Santos, L. Assessment of invasive fruit fly fruit infestation and damage in Cabo Delgado Province, Northern Mozambique. Afr. Crop. Sci. J. 2013, 21, 21-28.

11. Nankinga, C.M.; Isabirye, B.E.; Muyinza, H.; Rwomushana, I.; Stevenson, P.C.; Mayamba, A.; Aool, W.; Akol, A.M. Fruit fly infestation in mango: A threat to the Horticultural sector in Uganda. Uganda J. Agric. Sci. 2014, 15, 1-14.

12. Lux, S.A.; Copeland, R.S.; White, I.M.; Manrakhan, A.; Billah, M.K. A new invasive fruit fly species from the Bactrocera dorsalis (Hendel) group detected in East Africa. Int. J. Trop. Insect. Sci. 2003, 23, 355-361. [CrossRef]

13. Ekesi, S.; Lux, S.A.; Billah, M.K. Field comparison of food-based synthetic attractants and traps for African Tephritid fruit flies. In Development of Improved Attractants and Their Integration into Fruit Fly SIT Management Programmes; IAEA: Vienna, Austria, 2007; pp. 205-222.

14. Ekesi, S.; Nderitu, P.W.; Rwomushana, I. Field infestation, life history and demographic parameters of the fruit fly Bactrocera invadens (Diptera: Tephritidae) in Africa. Bull. Entomol. Res. 2006, 96, 379-386.

15. De Meyer, M.; Mohamed, S.A.; Virgilio, M.; Borgemeister, C. Taxonomy, ecology, and management of native and exotic fruit fly species in Africa. Ann. Rev. Entomol. 2016, 61, 219-238.

16. De Meyer, M.; Robertson, M.P.; Peterson, A.T.; Mansell, M.W. Ecological niches and potential geographical distributions of Mediterranean fruit fly (Ceratitis capitata) and Natal fruit fly (Ceratitis rosa). J. Biogeog. 2008, 35, 270-281. [CrossRef] 
17. Drew, R.A.I.; Tsuruta, K.; White, I.M. A new species of pest fruit fly (Diptera: Tephritidae: Dacinae) from Sri Lanka and Africa. Afr. Entomol. 2005, 13, 149-154.

18. Mwatawala, M.W.; De Meyer, M.; Makundi, R.H.; Maerere, A.P. An overview of Bactrocera (Diptera: Tephritidae) invasions and their speculated dominancy over native fruit fly species in Tanzania. J. Econ. Entomo. 2009, 6, 18-27. [CrossRef]

19. Ekesi, S.; Mohamed, S.A.; De Meyer, M. Fruit Fly Research and Development in Africa-Towards a Sustainable Strategy to Improve Horticulture; Springer International Publishing: Cham, Switzerland, 2016; p. 778.

20. Rwomushana, I.; Ekesi, S.; Gordon, I.; Ogol, C.K. Host plants and host plant preference studies for Bactrocera invadens (Diptera: Tephritidae) in Kenya, a new invasive fruit fly species in Africa. Ann. Entomol. Soc. Am. 2008, 101, 331-340. [CrossRef]

21. Lysandrou, M. Fruit flies in the Mediterranean and Arab world: How serious a threat are they and how can we minimize their impact. Arab. J. Plant. Prot. 2009, 27, 236-239.

22. Kheder, S.B.; Trabelsi, I.; Aouadi, N. From chemicals to IPM against the Mediterranean fruit fly Ceratitis capitata (Diptera, Tephritidae). In Integrated Pest Management and Pest Control-Current and Future Tactics; Larramendy, M.L., Soloneski, S., Eds.; InTech: Rijeka, Croatia, 2012; pp. 301-320.

23. Boulahia-Kheder, S.; Chaabane-Boujnah, H.; Bouratbine, M.; Rezgui, S. IPM based on mass trapping systems: A control solution for Ceratitis capitata (Wiedemann, 1824) (Diptera: Tephritidae) in organic citrus orchard of Tunisia. Res. J. Agric. Environ. Manag. 2015, 4, 459-469.

24. Couso-Ferrer, F.; Arouri, R.; Beroiz, B.; Perera, N.; Cervera, A.; Navarro-Llopis, V.; Ortego, F. Cross-resistance to insecticides in a malathion-resistant strain of Ceratitis capitata (Diptera: Tephritidae). J. Econ. Entomol. 2011, 104, 1349-1356. [CrossRef]

25. Gill, H.K.; Garg, H. Pesticide: Environmental impacts and management strategies. In Pesticides-Toxic Effects; Solenski, S., Larramenday, M.L., Eds.; Intech: Rejeka, Croatia, 2014; pp. 187-230.

26. Mebdoua, S. Pesticide residues in fruits and vegetables. In Bioactive Molecules in Food. Reference Series in Phytochemistry; Mérillon, J.M., Ramawat, K., Eds.; Springer: Cham, Switzerland, 2018; pp. 1715-1753.

27. Muriithi, B.W.; Affognon, H.D.; Diiro, G.M.; Kingori, S.W.; Tanga, C.M.; Nderitu, P.W.; Mohamed, S.A.; Ekesi, S. Impact assessment of Integrated Pest Management (IPM) strategy for suppression of mango-infesting fruit flies in Kenya. Crop. Prot. 2016, 81, 20-29. [CrossRef]

28. Korir, J.K.; Affognon, H.D.; Ritho, C.N.; Kingori, W.S.; Irungu, P.; Mohamed, S.A.; Ekesi, S. Grower adoption of an integrated pest management package for management of mango-infesting fruit flies (Diptera: Tephritidae) in Embu, Kenya. Int. J. Trop. Insect. Sci. 2015, 35, 80-89. [CrossRef]

29. Grout, T.G. Cold and heat treatment technologies for post-harvest control of fruit flies in Africa. In Fruit Fly Research and Development in Africa-Towards a Sustainable Strategy to Improve Horticulture; Ekesi, S., Mohamed, S.A., De Meyer, M., Eds.; Springer International Publishing: Cham, Switzerland, 2016; pp. 465-473.

30. Kibira, M.; Affognon, H.; Njehia, B.; Muriithi, B.; Ekesi, S. Economic Evaluation of Integrated Management of Fruit Fly in Mango Production in Embu County, Kenya. Afr. J. Agric. Resour. Manag. 2015, 10, 343-353.

31. Midingoyi, S.K.G.; Kassie, M.; Muriithi, B.; Diiro, G.; Ekesi, S. Do farmers and the environment benefit from adopting integrated pest management practices? Evidence from Kenya. J. Agric. Econ. 2019, 70, 452-470. [CrossRef]

32. Muriithi, B.W.; Gathogo, N.; Rwomushana, I.; Diiro, G.; Mohamed Faris, S.; Khamis, F.; Tanga, C.; Ekesi, S. Farmers' knowledge and perceptions on fruit flies and willingness to pay for a fruit fly integrated pest management strategy in Gamo Gofa zone, Ethiopia. Int. J. Agric. Sustain. 2021, 19, 199-212. [CrossRef]

33. Wangithi, C.M.; Muriithi, B.W.; Belmin, R. Adoption and Dis-Adoption of Sustainable Agriculture: A case of farmers' innovations and integrated fruit fly management in Kenya. Agriculture 2021, 11, 338. [CrossRef]

34. Okello, J. Tracking Indirect Beneficiaries of Complex Development Interventions in Agriculture; Technical Report for International Potato Centre (CIP): Lima, Peru, 2019; p. 19.

35. Hijmans, R.J.; van Etten, J. Geographic analysis and modeling with raster data. In $R$ Package Version 2.0-12; CRAN: Windhoek, Namibia, 2012. Available online: http:/ /CRAN.R--project.org/package=raster (accessed on 17 November 2021).

36. Food and Agriculture Organization of the United Nations. 2019. Production: Crops. Available online: http://faostat.fao.org (accessed on 17 November 2021).

37. R Core Team. R: A Language and Environment for Statistical Computing; R Foundation for Statistical Computing: Vienna, Austria, 2020. Available online: https:/ / www.R--project.org/ (accessed on 17 November 2021).

38. Ndlela, S.; Mwando, N.L.; Samira, A.; Mohamed, S.A. Advances in postharvest disinfestation of fruits and vegetables using hot water treatment technology-updates from Africa. In Postharvest Technology-Recent Advances, New Perspectives and Applications; IntechOpen: London, UK, 2021.

39. Muriithi, B.W.; Gathogo, N.G.; Diiro, G.M.; Mohamed, S.A.; Ekesi, S. Potential Adoption of Integrated Pest Management Strategy for Suppression of Mango Fruit Flies in East Africa: An Ex-Ante and Ex Post Analysis in Ethiopia and Kenya. Agriculture 2020, 10, 278. [CrossRef]

40. Boulahia-Kheder, S.; Loussaïef, F.; Ben Hmidène, A.; Trabelsi, I.; Jrad, F.; Akkari, Y.; Fezzani, M. Evaluation of two IPM programs based on mass-trapping against the Mediterranean fruit fly Ceratitis capitata on citrus orchards. Tunis. J. Plant Prot. 2012, 7, 55-68.

41. International Assessment of Agricultural Knowledge, Science and Technology for Development (IAASTD). Agriculture at a Crossroads: Global Report. Available online: https://wedocs.unep.org/handle/20.500.11822/8590 (accessed on 20 November 2021). 
42. Glover, D.; Venot, J.P.; Maat, H. On the movement of agricultural technologies packaging, unpacking and situated reconfiguration. In Agronomy for Development: The Politics of Knowledge in Agricultural Research; Sumberg, J., Ed.; Abingdon: Routledge, UK, 2017; pp. 14-30.

43. Ajayi, M.T.; Fatunbi, A.O.; Akinbamijo, O.O. Strategies for Scaling Agricultural Technologies in Africa; Forum for Agricultural Research in Africa (FARA): Accra, Ghana, 2018; pp. 1-180.

44. Boulahia-Kheder, S.; Turki, S.; Gouay, M.; Limem, E. Assessment of IPM against the Mediterranean fruit fly implemented at regional scale in Tunisia. IOBC WPRS Bull. 2018, 132, 177-184.

45. Liquido, N.J. Fruits on the ground as reservoir of resident melon fly (Diptera: Tephritidae) populations in papaya orchards. Environ. Entomol. 1991, 20, 620-625. [CrossRef]

46. Allwood, A.J. Control strategies for fruit flies (Family Tephritidae) in the South Pacific. In Management of Fruit Flies in the Pacific. A Regional Symposium, Nadi, Fiji, Australia, 28-31 October 1996; Australian Centre for International Agricultural Research: Canberra, Australia, 1997; pp. 171-178.

47. Jang, E.B.; Klungness, L.M.; McQuate, G.T. Extension of the use of Augmentoria for sanitation in a cropping system susceptible to the alien Tephritid fruit flies (Diptera: Terphritidae) in Hawaii. J. Appl. Sci. Environ. Manag. 2007, 11, $239-248$.

48. Klungness, L.M.; Jang, E.B.; Mau, R.F.L.; Vargas, R.I.; Sugano, J.S.; Fujitani, E. Sanitation techniques for controlling Tephritid fruit flies (Diptera: Tephritidae) in Hawaii. J. Appl. Sci. Environ. Manag. 2005, 9, 5-14. [CrossRef]

49. Ekesi, S.; Billah, M.K. A Field Guide to the Management of Economically Important Tephritid Fruit Flies in Africa, 2nd ed.; ICIPE Science Press: Nairobi, Kenya, 2007; pp. 1-577.

50. Allwood, A.J.; Drew, R.A.I. Management of fruit flies in the Pacific. In Management of Fruit Flies in the Pacific. A Regional Symposium, Nadi, Fiji, Australia, 28-31 October 1996; Australian Centre for International Agricultural Research: Canberra, Australia, 1997.

51. Steiner, L.F.; Rohwer, G.G.; Ayers, E.L.; Christenson, L.D. The role of attractants in the recent Mediterranean fruit fly eradication program in Florida. J. Econ. Entomol. 1961, 54, 30-35. [CrossRef]

52. Ekesi, S.; Tanga, C.T. Waste brewer's yeast as an alternative source of protein for use as a bait in the management of tephritid fruit flies. In Fruit Fly Research and Development in Africa-Towards a Sustainable Strategy to Improve Horticulture; Ekesi, S., Mohamed, S.A., De Meyer, M., Eds.; Springer International Publishing: Cham, Switzerland, 2016; pp. 293-306.

53. Bagheri, A.; Kolyaee, R.; Seyahooei, M.; Najafabadi, S.S.M.; Faraji, G. Efficacy of methyl eugenol bait traps for controlling the mango fruit fly Bactrocera zonata (Diptera: Tephritidae). J. Crop. Prot. 2017, 6, 181-189.

54. Cunningham, R.T. Male annihilation. In Fruit Flies-Their Biology, Natural Enemies and Control; Robinson, A.S., Hooper, G., Eds.; Elsevier: Amsterdam, The Netherlands, 1989; Volume 3B, pp. 345-351.

55. Maniania, J.N.K.; Ekesi, S. Development and application of mycoinsecticides for the management of fruit flies in Africa. In Fruit Fly Research and Development in Africa-Towards a Sustainable Strategy to Improve Horticulture; Ekesi, S., Mohamed, S.A., De Meyer, M., Eds.; Springer International Publishing: Cham, Switzerland, 2016; pp. 307-324.

56. Shilomboleni, H.; De Plaen, R. Scaling up research-for-development innovations in food and agricultural systems. Dev. Pract. 2019, 29, 723-734. [CrossRef]

57. East African Community (EAC) harmonized guidelines for the Registration of Biopesticides and Bio Control Agents for plant protection. Available online: http:/ / repository.eac.int/handle/11671/24128 (accessed on 28 November 2019).

58. Mohamed, S.A.; Ramadan, M.M.; Ekesi, S. In and out of Africa: Parasitoids used for biological control of fruit flies. In Fruit Fly Research and Development in Africa-Towards a Sustainable Strategy to Improve Horticulture; Ekesi, S., Mohamed, S.A., De Meyer, M., Eds.; Springer International Publishing: Cham, Switzerland, 2016; pp. 325-368.

59. Mohamed, S.A.; Wharton, R.A.; von Mérey, G.; Schulthess, F. Acceptance and suitability of different host stages of Ceratitis capitata (Wiedemann) (Diptera: Tephritidae) and seven other tephritid fruit fly species to Tetrastichus giffardii Silvestri (Hymenoptera: Eulophidae). Biol. Control 2006, 39, 262-271. [CrossRef]

60. Wharton, R. Classification of the braconid subfamily Opiinae (Hymenoptera). Can. Entomol. 1988, 120, 333-360. [CrossRef]

61. Wharton, R.A. A review of the Old-World genus Fopius Wharton (Hymenoptera: Braconidae: Opiinae), with description of two new species reared from fruit-infesting Tephritidae (Diptera). J. Hymenopt. Res. 1999, 8, 48-64.

62. Vargas, R.I.; Leblanc, L.; Putoa, R.; Eitam, A. Impact of introduction of Bactrocera dorsalis (Diptera: Tephritidae) and classical biological control releases of Fopius arisanus (Hymenoptera: Braconidae) on economically important fruit flies in French Polynesia. J. Econ. Entomol. 2007, 100, 670-679. [CrossRef]

63. Vargas, R.I.; Leblanc, L.; McKenney, M.; Mackey, B.; Harris, E.J.; Badji, K. Rearing Fopius arisanus (Sonan) (Hymenoptera: Braconidae) on Mediterranean fruit fly and its introduction into Senegal against Oriental fruit fly (Diptera: Tephritidae). Proc. Hawaii. Entomol. Soc. 2016, 48, 85-94.

64. Mohamed, S.A.; Ekesi, S.; Hanna, R. Evaluation of the impact of Diachasmimorpha longicaudata on Bactrocera invadens and five African fruit fly species. J. Appl. Entomol. 2008, 132, 789-797. [CrossRef]

65. Mohamed, S.A.; Ekesi, S.; Hanna, R. Old and new host-parasitoid associations: Parasitism of the invasive fruit fly Bactrocera invadens (Diptera: Tephritidae) and five African fruit fly species by Fopius arisanus, an Asian opiine parasitoid. Biocontrol. Sci. Technol. 2010, 20, 183-196. [CrossRef]

66. Ekesi, S.; Billah, M.K.; Nderitu, P.W.; Lux, S.A.; Rwomushana IV, I. Evidence for competitive displacement of Ceratitis cosyra by the invasive fruit fly Bactrocera invadens (Diptera: Tephritidae) on mango and mechanisms contributing to the displacement. $J$. Econc. Entomol. 2009, 102, 981-991. [CrossRef] [PubMed] 
67. Ekesi, S. What can farmers do against fruit flies? Org. Farmer 2010, 59, 2-6.

68. Gnanvossou, D.; Hanna, R.; Bokonon-Ganta, A.H.; Ekesi, S.; Mohamed, S.A. Release, establishment and spread of the natural enemy Fopius arisanus (Hymenoptera: Braconidae) for control of the invasive oriental fruit fly Bactrocera dorsalis (Diptera: Tephritidae) in Benin, West Africa. In Fruit Fly Research and Development in Africa-Towards a Sustainable Strategy to Improve Horticulture; Ekesi, S., Mohamed, S.A., De Meyer, M., Eds.; Springer International Publishing: Cham, Switzerland, 2016; pp. 575-600.

69. Barnes, B.N. Sterile Insect Technique (SIT) for Fruit Fly Control-The South African Experience. In Fruit Fly Research and Development in Africa-Towards a Sustainable Management Strategy to Improve Horticulture; Ekesi, S., Mohamed, S., De Meyer, M., Eds.; Springer International Publishing: Cham, Switzerland, 2016; pp. 435-464.

70. Venter, J.-H.; Baard, C.; Barnes, B.N. Area-Wide Management of Mediterranean Fruit Fly with the Sterile Insect Technique in South Africa: New Production and Management Techniques Pay Dividends; CRC Press: Boca Raton, FL, USA, 2020; pp. $129-141$.

71. Klaussen, W. Area wide integrated pest management and the sterile insect technique. In Sterile Insect Technique Principles and Practices in Area Wide Pest Management; Dyck, V.A., Hendrichs, J., Robbinson, A.S., Eds.; Springer International Publishing: Cham, Switzerland, 2005; pp. 36-39.

72. Isabirye, B.; Nankinga, C.K.; Mayamba, A.; Akol, A.M.; Rwomushana, I. Integrated management of fruit flies-Case studies from Uganda. In Fruit Fly Research and Development in Africa-Towards a Sustainable Strategy to Improve Horticulture; Ekesi, S., Mohamed, S.A., De Meyer, M., Eds.; Springer International Publishing: Cham, Switzerland, 2016; pp. 497-515.

73. Umeh, V.; Onukwu, D. Integrated management of fruit flies: Case studies from Nigeria. In Fruit Fly Research and Development in Africa-Towards a Sustainable Strategy to Improve Horticulture; Ekesi, S., Mohamed, S.A., De Meyer, M., Eds.; Springer International Publishing: Cham, Switzerland, 2016; pp. 553-574.

74. Adamo, A. Participatory Agricultural Research Processes in Eastern and Central Ethiopia: Using Farmers' Social Networks as Entry Points for PR Activities. Network on Bean Research in Africa; Occasional Publications Series: Kampala, Uganda, 2001.

75. German, L.; Mowo, J.; Kingamkono, M. A methodology for tracking the "fate" of technological interventions in agriculture. Agric. Hum. Values 2006, 23, 353-369. [CrossRef]

76. Jemaa, J.M.B.; Bachrouch, O.; Allimi, E.; Dhouibi, M.H. Field evaluation of Mediterranean fruit fly mass trapping with Tripack ${ }^{\circledR}$ as alternative to malathion bait-spraying in citrus orchards. Span. J. Agric. Res. 2010, 8, 400-408. [CrossRef]

77. Asfers, A.; Joutei, A.B.; Boughdad, A.; Blenzar, A.; Lahlali, R.; Houssa, A.A. Comparative efficacy of mass trapping and attractand-kill technique in the control of medfly (Ceratitis capitata, Wiedemann) in Central Moroccan peach orchard. Pestic. Phytomed. 2018, 33, 53-63. [CrossRef]

78. Van Mele, P.; Vayssières, J.-F.; Van Tellingen, E.; Vrolijks, J. Effects of an African weaver ant, Oecophylla longinoda, in controlling mango fruit flies (Diptera Tephritidae) in Benin. J. Econ. Entomol. 2007, 100, 695-701.

79. Vayssières, J.-F.; Offenberg, J.; Sinzogan, A.; Adandonon, A.; Wargui, R.; Anato, F.; Houngbo, H.Y.; Ouagoussounon, I.; Diamé, L.; Quilici, S.; et al. The use of weaver ants in the management of fruit flies in Africa. In Fruit Fly Research and Development in Africa-Towards a Sustainable Strategy to Improve Horticulture; Ekesi, S., Mohamed, S., De Meyer, M., Eds.; Springer International Publishing: Cham, Switzerland, 2016; pp. 389-434.

80. Cowen, R. Tortoises and hares: Choice among technologies of unknown merit. Econ. J. 1991, 101, 801-814. [CrossRef]

81. Cowen, R.; Gunby, P. Sprayed to death: Path dependence, lock-in and pest-control strategies. Econ. J. 1996, 106, 521-542. [CrossRef]

82. Deguine, J.-P.; Aubertot, J.-N.; Flor, R.J.; Lescourret, F.; Wyckhuys, K.A.G.; Ratnadass, A. Integrated pest management: Good intentions, hard realities. A review. Agron. Sustain. Dev. 2021, 41, 38. [CrossRef]

83. Alwang, J.; Norton, G.; Larochelle, C. Obstacles to widespread diffusion of IPM in developing countries: Lessons from the field. J. Integ. Pest. Manag. 2019, 10, 10. [CrossRef]

84. Morse, S.; Buhler, W. IPM in developing countries: The danger of an ideal. Integr. Pest Manag. Rev. 1997, 2, 175-185. [CrossRef]

85. Rebaudo, F.; Carpio, C.; Crespo-Pérez, V.; Herrera, M.; de Scurrah, M.M.; Canto, R.C.; Montañez, A.G.; Bonifacio, A.; Mamani, M.; Saravia, R.; et al. Agent-based models and integrated pest management diffusion in small scale farmer communities. In Integrated Pest Management; Springer: Dordrecht, The Netherlands, 2014; pp. 367-383. 